\title{
Edible Films and Coatings for Fresh Fish Packaging: Focus on Quality Changes and Shelf-life Extension
}

\author{
Maria-Ioana Socaciu 1@ , Cristina Anamaria Semeniuc ${ }^{2, *}$ (D) and Dan Cristian Vodnar ${ }^{1, *}$ \\ 1 Department of Food Science, University of Agricultural Sciences and Veterinary Medicine Cluj-Napoca, \\ 3-5 Mănăştur St., 400372 Cluj-Napoca, Romania; maria-ioana.socaciu@usamvcluj.ro \\ 2 Department of Food Engineering, University of Agricultural Sciences and Veterinary Medicine Cluj-Napoca, \\ 3-5 Mănăştur St., 400372 Cluj-Napoca, Romania \\ * Correspondence: cristina.semeniuc@usamvcluj.ro (C.A.S.); dan.vodnar@usamvcluj.ro (D.C.V.); \\ Tel.: +40-264-596-384 (C.A.S. \& D.C.V.)
}

Received: 16 August 2018; Accepted: 13 October 2018; Published: 16 October 2018

check for updates

\begin{abstract}
Fresh fish is extensively consumed and is one of the most-traded food commodities in the world. Conventional preservation technologies include vacuum and modified atmosphere packaging, but they are costly since requires capital investment. In the last decade, research has been directed towards the development of antimicrobial packaging systems, as an economical alternative to these. This paper outlines antimicrobial films and coatings applied so far on fresh fish, their efficacy against targeted microorganism/group and effects on chemical quality of the product. Findings show that edible films/coatings incorporated with different active agents applied to fresh fish are able to inhibit the microbial growth and decrease the rate of fish nutrients degradation, thus preventing the formation of chemical metabolites; a shelf-life extension of 6 to 13 days was obtained for fish fillets, depending on the species on which the active packaging materials were applied. The manufacturing use of these formulations could lead to a significant reduction in fish waste, consequently, a diminution of economic losses for fish traders and retailers. Therefore, their industrial production and commercialization could be an exploitable sector by the packaging industry.
\end{abstract}

Keywords: edible films; edible coatings; antimicrobial agents; fresh fish; spoilage; shelf-life

\section{Introduction}

Fish is one of the most-traded food commodities worldwide [1]. Capture fisheries and aquaculture provide valuable economic and social benefits to those who work in these industries [2]. However, post-harvest handling, processing, and storage of fish lead to food losses and waste [3]. Post-harvest losses occur at all stages in the fish supply chain from capture to consumer [4]. The losses can be physical, economical, or nutritional and are caused by spoilage or poor processing [5]. Spoilage is the process in which fish deteriorates to the point that becomes unacceptable for human consumption (with altered taste, smell, appearance, or texture) [6]. Globally, fish losses that are caused by spoilage account for around 10\% (10 to 12 million tons per year) of the total production from capture fisheries and aquaculture [7].

Fresh fish is a highly perishable product due to its high water activity, nutrient availability, nearly neutral-pH (factors that influence microbial growth) and the presence of autolytic enzymes; hence, it is susceptible to post-harvest losses [8,9]. Under normal refrigerated storage conditions, its shelf-life is limited by the development of enzymatic (caused by endogenous or microbial enzymes) and chemical reactions [10]. The main initial causative factor for fish spoilage is microbial growth and invasion, followed by the autolytic enzymes and then by chemical reactions, such as oxidation or hydrolysis $[11,12]$. 
Post-harvest losses of fresh fish due to microbial spoilage are a matter of great importance to the fishing industry [13]. So, specific requirements and preservation techniques are needed to minimize the activity of spoilage bacteria. Fresh fish products are presently stored on ice or under refrigeration during their distribution and marketing. In these conditions, their shelf-life is limited to 5-10 days (depending on species, harvest location, and season) and they can result in enormous economic losses to fish traders and retailers $[14,15]$. Therefore, the fish-process industry is actively seeking alternative methods of shelf-life preservation and marketability of fresh fish [16].

Packaging plays a critical role in the fish supply chain and is part of the solution to tackle food waste $[17,18]$. Vacuum packaging (VP) and modified atmosphere packaging (MAP) are very commonly used as a supplement to ice or refrigeration to inhibit the normal spoilage flora and extend the shelf-life of fresh fish products $[14,19,20]$. MAP technology has, however, some disadvantages, such as added costs for packaging equipment, gases, and packaging materials; it also requires special training for food operators [21].

Packaging innovation and new technologies is a necessity for the fishing industry. In recent years, a variety of active packaging systems have been developed to prolong storage life and enhance the safety of fish products. These have a variety of advantages such as biodegradability, edibility, biocompatibility, and aesthetic appearance, respectively, barrier properties against oxygen and physical stress [22]. The purpose of this paper is to provide an overview of published research about edible films and coatings applied to fresh fish. The antimicrobial films and coatings that are used for fish packaging and their effects on chemical quality of fresh fish are reviewed and discussed (Figure 1).
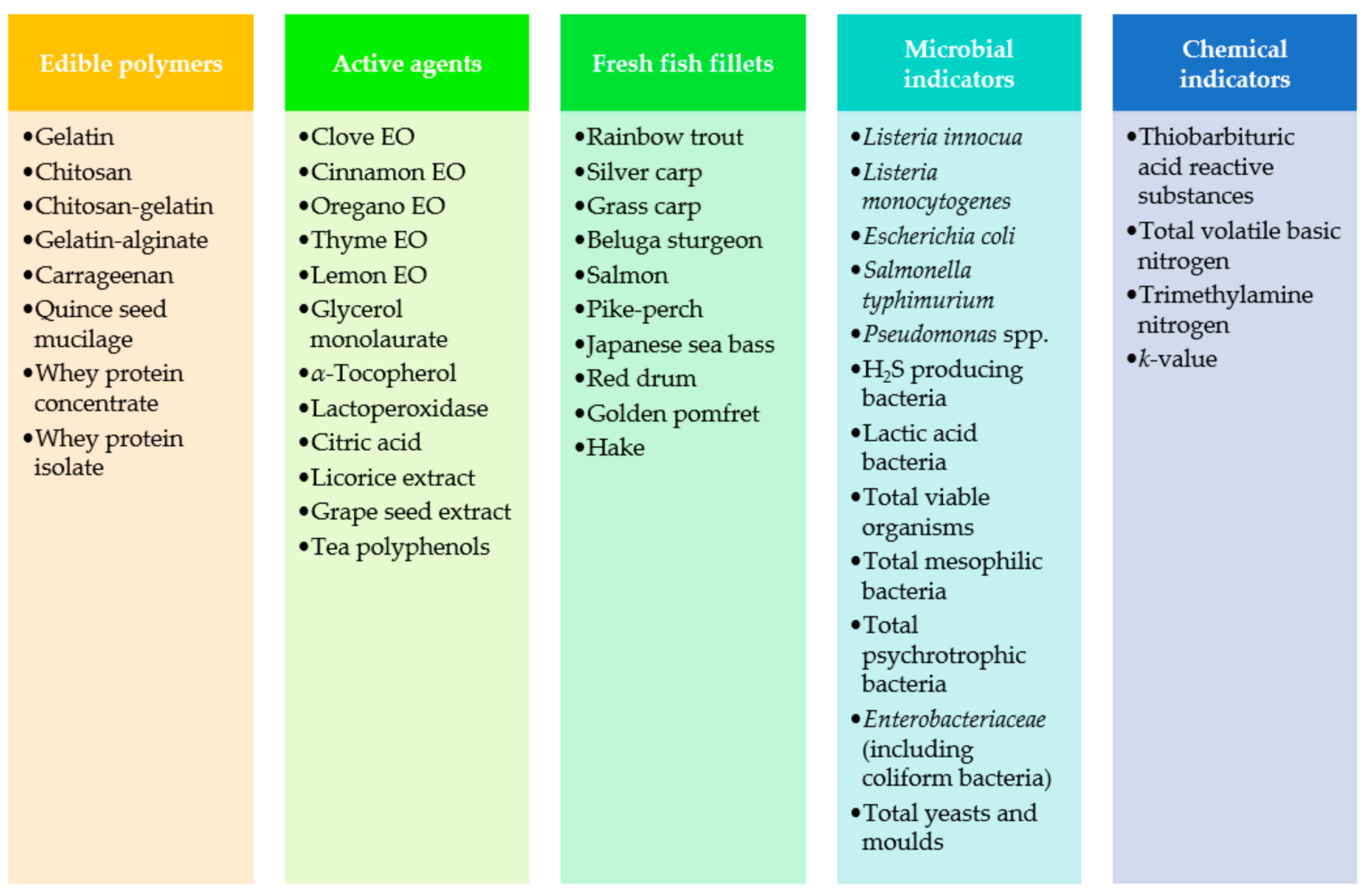

Figure 1. Antimicrobial films and coatings used to extend the shelf-life of fresh fish fillets.

\section{Microbiological Issues}

Fresh fish spoils due to the action of a group of microorganisms, the so-called specific spoilage organisms (SSOs). These organisms have the ability to dominate the fish flora and produce metabolites that directly affect the sensory properties of the product resulting in its rejection by consumers [23]. During storage, the microflora changes owing to different capacities of the microorganisms to tolerate the preservation conditions [24]. Under aerobic iced storage, the flora of fish is composed almost 
exclusively of Pseudomonas spp. and Shewanella putrefaciens (SSOs) regardless of whether it was caught or harvested in temperate or sub-tropical and tropical waters. At ambient temperature $\left(25^{\circ} \mathrm{C}\right)$, microflora is dominated by mesophilic Vibrionaceae, and, particularly if the fish is caught in polluted waters, by mesophilic Enterobacteriaceae [25].

Microbial spoilage is due to the proliferation of microorganisms after the death of fish as a result of the immune system collapsing, followed by the microbial invasion of the fish body through the skin [12]. Fish have a unique osmoregulatory mechanism to avoid dehydration in marine environments and waterlogging of tissue in freshwater; it contains osmoregulatory compounds, like trimethylamine oxide (TMAO) and urea [26]. Microbial enzymes that are present in fish can break down TMAO to trimethylamine (TMA) and urea to ammonia, volatile organic compounds associated with microbial spoilage [12]. Many other volatile compounds can be formed by microbial enzymatic degradation of other substrates, such as hydrogen sulphide (from cysteine), methanethiol and methyl sulphide (from methionine), histamine (from histidine), acetate, carbon dioxide and water (from carbohydrates and lactate), hypoxanthine (from inosine and inosine- $5^{\prime}$-monophosphate), esters, ketones, aldehydes (from amino acids, like glycine, serine, and leucine), as well as ammonia (from amino acids and urea) [12,26]. These molecules are responsible for sweet, fruity, ammonia-like, putrid, and sulphuric off-flavours in spoiled fish [27].

\section{Antimicrobial Films and Coatings Applied on Fresh Fish}

This chapter provides an overview of previous research on the antimicrobial packaging of fresh fish. Table 1 lists active edible films and coatings applied to fresh fish fillets (of rainbow trout, silver carp, grass carp, beluga sturgeon, salmon, pike-perch, Japanese sea bass, red drum, golden pomfret, and hake) to extend its shelf-life. These films and coatings were produced from edible polymers like gelatin, chitosan, chitosan-gelatin, gelatin-alginate, carrageenan, quince seed mucilage, whey protein concentrate, and whey protein isolate incorporated with various active agents (essential oils (EOs) of clove, cinnamon, oregano, thyme, and lemon, glycerol monolaurate, $\alpha$-tocopherol, lactoperoxidase, citric acid, licorice extract, grape seed extract, and tea polyphenols). Their antimicrobial efficacy was investigated in situ against spoilage and pathogenic microorganisms. Different levels of effectiveness were noticed, depending on the active agent used, its concentration, storage temperature, atmosphere composition (normal or modified), and targeted microorganism/group.

\subsection{Efficacy against Tested Microorganism/Group at the End of Monitoring Time}

\subsubsection{Efficacy against Spoilage Microorganisms}

Several authors have investigated the potential of edible films/coatings in extending the shelf-life of fresh fish fillets by retarding the growth of spoilage bacteria. Jouki et al. (2014) [28] have tested the efficacy of films based on $1 \%$ quince seed mucilage incorporated with different concentrations of oregano and thyme EOs ( $1 \%, 1.5 \%$, and $2 \%$ ) against Pseudomonas spp., $\mathrm{H}_{2} \mathrm{~S}$ producing bacteria, and lactic acid bacteria in rainbow trout fillets; Kazemi \& Rezaei (2015) [29] of films based on 3\% gelatin and $1.5 \%$ alginate containing $1.5 \%$ oregano EO against Pseudomonas spp. and lactic acid bacteria; Volpe et al. (2015) [30] of the coating based on 1\% carrageenan incorporated with $1 \%$ lemon EO against $\mathrm{H}_{2} \mathrm{~S}$ producing bacteria and lactic acid bacteria; Yıldız \& Yang1lar (2016) [31] of coatings based on $8 \%$ whey protein concentrate/glycerol in ratios of 1:1 and 2:1 against lactic acid bacteria. On grass carp fillets, Yu et al. (2017) [32] have evaluated the efficacy of coatings based on $2 \%$ chitosan incorporated with different concentrations of glycerol monolaurate $(0.1 \%$ and $0.3 \%)$ against Pseudomonas spp. and $\mathrm{H}_{2} \mathrm{~S}$ producing bacteria. In a study on pike-perch fillets, Shokri \& Ehsani (2017) [33] have tested the efficacy of coatings based on 10\% whey protein isolate incorporated with $2.5 \%$ lactoperoxidase, $1.5 \%$ and $3.0 \% \alpha$-tocopherol, respectively, combinations of lactoperoxidase and $\alpha$-tocopherol (2.5\%/1.5\% and 2.5\%/3.0\%) against Pseudomonas spp. and $\mathrm{H}_{2} \mathrm{~S}$ producing bacteria. 
Edible films/coatings incorporated with 2\% thyme EO [28], 1.5\% oregano EO [29], respectively $1 \%$ lemon EO [30] applied on rainbow trout fillets, $0.3 \%$ glycerol monolaurate [32] on grass carp fillets, and 2.5\% lactoperoxidase [33] on pike-perch fillets have been proven to be the most effective against $P$ seudomonas spp. The most effective against $\mathrm{H}_{2} \mathrm{~S}$ producing bacteria were edible films/coatings incorporated with $2 \%$ thyme EO [28] applied on rainbow trout fillets, $0.3 \%$ glycerol monolaurate [32] on grass carp fillets, and $2.5 \%$ lactoperoxidase [33] on pike-perch fillets, but against lactic acid bacteria, the ones incorporated with $2 \%$ thyme EO [28], 1.5\% oregano EO [29], 1\% lemon EO [30], and 8\% whey protein concentrate/glycerol, 2:1 [31] applied on rainbow trout fillets.

In a recent study, Carrión-Granda et al. (2018) [34] have examined the efficacy of coatings based on $10 \%$ whey protein isolate incorporated with different concentrations of oregano and thyme EOs $(1 \%$ and $3 \%$ ) under air and MAP conditions against Pseudomonas spp., $\mathrm{H}_{2} \mathrm{~S}$ producing bacteria, and lactic acid bacteria in hake fillets. The application of coating with $1 \%$ thyme EO under MAP has shown the best results against Pseudomonas spp. but against $\mathrm{H}_{2} \mathrm{~S}$ producing bacteria and lactic acid bacteria, the one with $3 \%$ oregano EO under the MAP. Different inhibitory effects displayed by an essential oil against various bacteria are most probably due to its chemical composition [35]. The antimicrobial mechanism of action of plant EOs is related to the hydrophobicity of their components [36], which enables them to migrate in the lipids of the bacterial cell membrane and mitochondria, disturbing their structures and rendering them more permeable [37]; leakage of ions and intracellular constituents can thus occur [38].

\subsubsection{Efficacy against Pathogenic Microorganisms}

According to current literature, few studies on the efficacy of active packaging materials against pathogenic microorganisms in fresh fish have been published. Findings of such in situ investigations are presented in Table 1. Gómez-Estaca et al. (2009) [39] have tested the efficacy of edible films based on $8 \%$ gelatin and $8 \%$ gelatin/chitosan, both incorporated with $7.5 \%$ clove EO on salmon fillets, in vitro against Listeria innocua and Escherichia coli, then in situ against total viable organisms. The film based on gelatin was more effective against both bacteria than the one based on gelatin/chitosan; the ionic and hydrogen bonds that were formed between gelatin and chitosan diminished the solubility of the resulting film, thus reducing the amount of clove EO released. However, in the in situ experiment, they used the film based on gelatin/chitosan for storage trials. Their previous studies revealed that the low water solubility of the gelatin/chitosan matrix gives the film stability under fish contact conditions during chilled storage.

There are also some studies on fish fillets challenged with pathogenic bacteria. Han et al. (2013) [40] have investigated the efficacy of films based on $6.75 \%(w / w)$ gelatin, with and without nisin-incorporated, against Listeria monocytogenes in rainbow trout fillets that were challenged with $2 \log$ CFU/g inoculum before and after coating. The edible film incorporated with $18 \mu \mathrm{g} / \mathrm{cm}^{2}$ nisin, applied before inoculation, showed the highest inhibitory effect on Listeria monocytogenes.

The efficacy of gelatin coatings containing different concentrations of oregano $\mathrm{EO}(0.5 \%, 1.0 \%$, and $2.0 \% v / v$ ) was also investigated by Min and Oh (2009) [41], in catfish fillets that were inoculated with Salmonella typhimurium and Escherichia coli O157:H7. The coating based on 3\% $(w / v)$ gelatin containing $2 \%$ oregano EO exhibited the best inhibitory effect on both bacteria.

\subsubsection{Efficacy against Spoilage and/or Pathogenic Microorganisms}

The following groups of microorganisms we have included into this category: total viable organisms, total mesophilic bacteria, total psychrotrophic bacteria, Enterobacteriaceae (including coliform bacteria), respectively total yeasts and moulds. Against total viable organisms, the most effective edible films / coatings were those that were incorporated with $2 \%$ thyme EO [28], $1.5 \%$ oregano EO [29], 1\% lemon EO [30], and 1.5\% cinnamon EO [42] applied on rainbow trout fillets, $0.3 \%$ glycerol monolaurate [32] on grass carp fillets, $2.5 \%$ lactoperoxidase [33] on pike-perch fillets, $0.2 \%$ tea polyphenols [43] on red drum fillets, $0.5 \%$ citric acid on Japanese sea bass fillets [44] and beluga sturgeon fillets [45], and 3\% oregano EO under MAP conditions [34] on hake fillets. Edible coatings 
based on chitosan [46] applied to salmon fillets, respectively chitosan-gelatin [47] to golden pomfret fillets exhibited an antimicrobial effect compared to uncoated controls.

Regarding total psychrotrophic bacteria, the most effective were edible films/coatings incorporated with $2 \%$ thyme EO [28], 1.5\% oregano EO [29], and 1.5\% cinnamon EO [42] applied on rainbow trout fillets, $0.3 \%$ glycerol monolaurate [32] on grass carp fillets, $1.5 \%$ cinnamon EO on beluga sturgeon fillets [45], and $2.5 \%$ lactoperoxidase [33] on pike-perch fillets.

Edible coatings with $8 \%$ whey protein concentrate/glycerol, 2:1 applied on rainbow trout fillets [31], $1 \%$ chitosan [48] on salmon fillets, and $2 \%$ nanochitosan on silver carp fillets [49] have shown to be effective against both total psychrotrophic bacteria and total mesophilic bacteria.

The most effective edible films/coatings against Enterobacteriaceae (including coliform bacteria) were those incorporated with 2\% thyme EO [28], 1.5\% oregano EO [29], and 1\% lemon EO [30] that were applied on rainbow trout fillets. Edible coating with $8 \%$ whey protein concentrate/glycerol, 2:1 has also shown to be effective against Enterobacteriaceae in rainbow trout fillets as compared with the other formulations tested in the study [31].

When tested against total yeasts and moulds, the edible coating based on $0.4 \%$ chitosan and $3.6 \%$ gelatin applied to golden pomfret fillets was the most effective among all formulations [47].

In the work of Carrión-Granda et al. (2018) [34], the edible coating incorporated with 3\% oregano EO was the most effective against total viable organisms, total psychrotrophic bacteria, as well as Enterobacteriaceae when applied under the MAP conditions.

The results of these investigations are not comparable, since, on the same fish species, were applied edible films/coatings with different polymer matrices, respectively active agents and evaluated in different storage conditions (temperature, atmosphere composition, and storage time). We noticed, however, some tendencies that allow us to affirm that:

- edible films/coatings with the highest concentration of active agent tested have shown the greatest antimicrobial efficacy;

- antimicrobial films/coatings were more effective at lower temperatures when tested in different storage temperature conditions; and,

- under modified atmosphere packaging conditions, antimicrobial films/coatings were more effective than under air conditions.

Other authors have noticed that the effectiveness of antimicrobial packaging material depends also on the initial microbial load [40], chemical composition, and $\mathrm{pH}$ of tested food products [37]. Generally, the susceptibility of bacteria to the antimicrobial effect of EOs is increased in products with low-fat content and low $\mathrm{pH}$, respectively. 
Table 1. Antimicrobial films and coatings used for packaging fish.

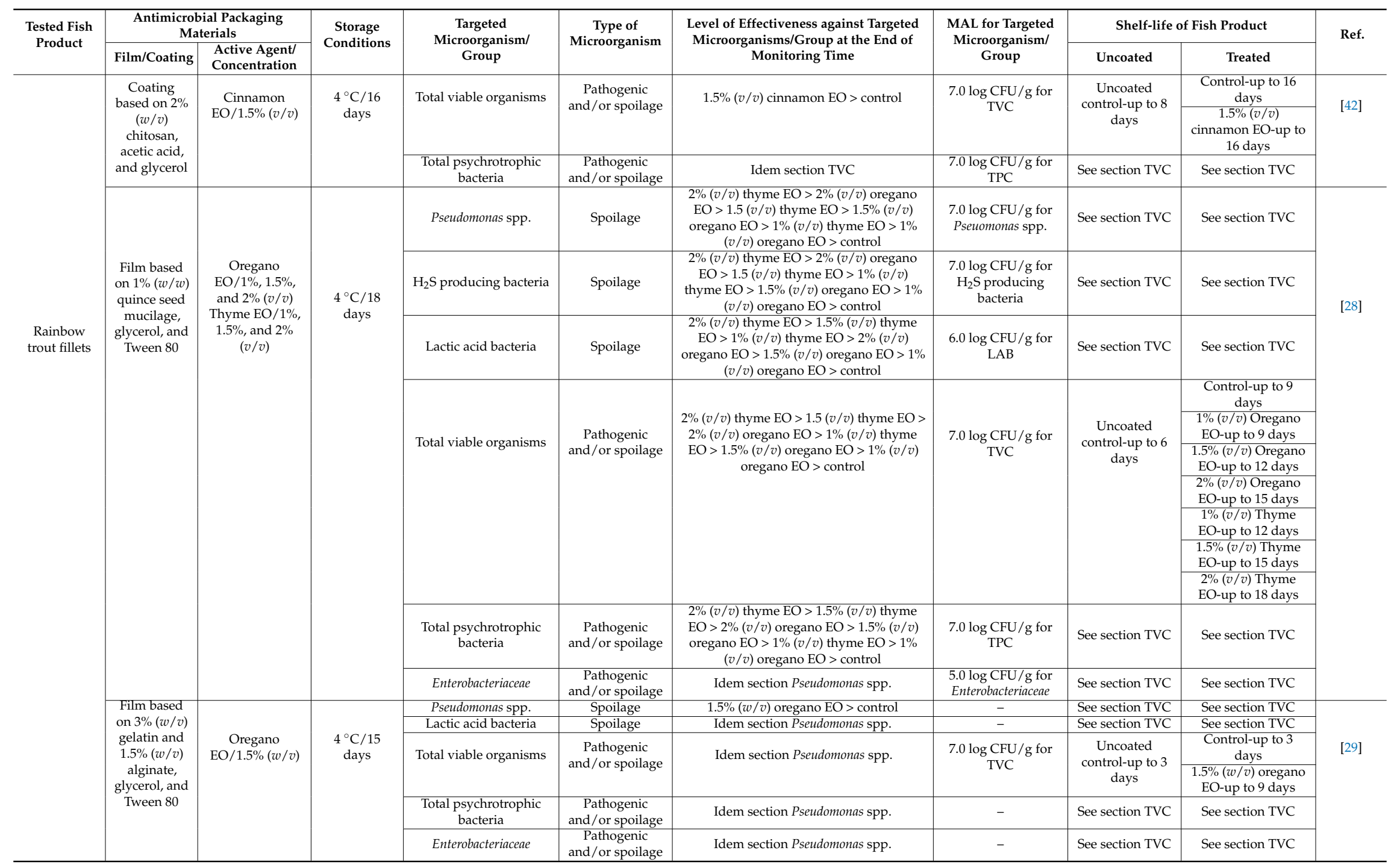


Table 1. Cont

\begin{tabular}{|c|c|c|c|c|c|c|c|c|c|c|}
\hline \multirow{2}{*}{$\begin{array}{c}\text { Tested Fish } \\
\text { Product }\end{array}$} & \multicolumn{2}{|c|}{ Antimicrobial Packaging Materials } & \multirow{2}{*}{$\begin{array}{c}\text { Storage } \\
\text { Conditions }\end{array}$} & \multirow{2}{*}{$\begin{array}{l}\text { Targeted } \\
\text { Microorganism/ } \\
\text { Group }\end{array}$} & \multirow{2}{*}{\begin{tabular}{|c|} 
Type of \\
Microorganism
\end{tabular}} & \multirow{2}{*}{$\begin{array}{l}\text { Level of Effectiveness against Targeted } \\
\text { Microorganisms/Group at the End of } \\
\text { Monitoring Time }\end{array}$} & \multirow{2}{*}{$\begin{array}{l}\text { MAL for Targeted } \\
\text { Microorganism/ } \\
\text { Group }\end{array}$} & \multicolumn{2}{|c|}{ Shelf-life of Fish Product } & \multirow{2}{*}{ Ref. } \\
\hline & Film/Coating & $\begin{array}{l}\text { Active Agent/ } \\
\text { Concentration }\end{array}$ & & & & & & Uncoated & Treated & \\
\hline & \multirow{4}{*}{$\begin{array}{l}\text { Coating based on } \\
1 \%(w / w) \\
\text { carrageenan }\end{array}$} & \multirow{4}{*}{$\begin{array}{l}\text { Lemon EO/1\% } \\
(w / w)\end{array}$} & \multirow{4}{*}{$\begin{array}{l}4^{\circ} \mathrm{C} / 15 \\
\text { days }\end{array}$} & $\mathrm{H}_{2} \mathrm{~S}$ producing bacteria & Spoilage & $1 \%(w / w)$ lemon $\mathrm{EO}>$ control & - & See section TVC & See section TVC & \multirow{4}{*}{ [30] } \\
\hline & & & & Lactic acid bacteria & \begin{tabular}{|c|} 
Spoilage \\
Pathogenic
\end{tabular} & Idem section $\mathrm{H}_{2} \mathrm{~S}$ producing bacteria & $\frac{-}{7.0 \log \mathrm{CFU} / \mathrm{g} \text { for }}$ & $\begin{array}{c}\text { See section TVC } \\
\text { Uncoated }\end{array}$ & $\begin{array}{l}\text { See section TVC } \\
\text { Control-up to } 12 \text { days }\end{array}$ & \\
\hline & & & & Total viable organisms & and/or spoilage & Idem section $\mathrm{H}_{2} \mathrm{~S}$ producing bacteria & TVC & $\begin{array}{c}\text { control-up to } 3 \\
\text { days }\end{array}$ & $\begin{array}{l}1 \%(w / w) \text { lemon EO-up } \\
\text { to } 15 \text { days }\end{array}$ & \\
\hline & & & & Enterobacteriaceae & $\begin{array}{c}\text { Pathogenic } \\
\text { and/or spoilage }\end{array}$ & Idem section $\mathrm{H}_{2} \mathrm{~S}$ producing bacteria & - & See section TVC & See section TVC & \\
\hline & \multirow[t]{2}{*}{$\begin{array}{c}\text { Coating based on } \\
8 \%(w / w) \text { whey } \\
\text { protein concentrate }\end{array}$} & \multirow{5}{*}{ - } & \multirow{5}{*}{$\begin{array}{c}4^{\circ} \mathrm{C} / 15 \\
\text { days }\end{array}$} & Lactic acid bacteria & Spoilage & $\begin{array}{c}8 \%(w / w) \text { whey protein } \\
\text { concentrate/glycerol, } 2: 1>8 \%(w / w) \\
\text { whey protein concentrate/glycerol, } 1: 1> \\
8 \%(w / w) \text { whey protein concentrate }\end{array}$ & - & See section TMC & See section TMC & \multirow{5}{*}{ [31] } \\
\hline & & & & $\begin{array}{l}\text { Total mesophilic } \\
\text { bacteria }\end{array}$ & $\begin{array}{l}\text { Pathogenic } \\
\text { and/or spoilage }\end{array}$ & Idem section LAB & - & $\begin{array}{l}\text { Uncoated } \\
\text { control-up to } 9 \\
\text { days }\end{array}$ & $\begin{array}{c}8 \%(w / w) \text { whey protein } \\
\text { concentrate-up to } 12 \\
\text { days } \\
8 \%(w / w) \text { whey protein } \\
\text { concentrate / glycerol, } \\
1: 1-\text {-up to } 15 \text { days }\end{array}$ & \\
\hline & \multirow{3}{*}{\begin{tabular}{c|} 
Coating based on \\
$8 \%(w / w)$ whey \\
protein \\
concentrate/glycerol, \\
$1: 1$ and $2: 1$
\end{tabular}} & & & & & & & & $\begin{array}{l}8 \%(w / w) \text { whey protein } \\
\text { concentrate/glycerol, } \\
\text { 2:1-up to } 15 \text { days }\end{array}$ & \\
\hline & & & & $\begin{array}{l}\text { Total psychrotrophic } \\
\text { bacteria }\end{array}$ & $\begin{array}{c}\text { Pathogenic } \\
\text { and/or spoilage }\end{array}$ & Idem section LAB & - & See section TMC & See section TMC & \\
\hline & & & & Enterobacteriaceae & $\begin{array}{l}\text { Pathogenic } \\
\text { and/or spoilage }\end{array}$ & $\begin{array}{l}8 \%(w / w) \text { whey protein } \\
\text { concentrate/glycerol, } 2: 1>8 \%(w / w) \\
\text { whey protein concentrate }>8 \%(w / w) \\
\text { whey protein concentrate } / \text { glycerol, } 1: 1\end{array}$ & - & See section TMC & See section TMC & \\
\hline \multirow{3}{*}{$\begin{array}{l}\text { Silver carp } \\
\text { fillets }\end{array}$} & \multirow{2}{*}{$\begin{array}{l}\text { Coating based on } \\
2 \%(w / v) \text { chitosan } \\
\text { and glycerol }\end{array}$} & & \multirow{3}{*}{$\begin{array}{l}4{ }^{\circ} \mathrm{C} / 12 \\
\text { days }\end{array}$} & $\begin{array}{c}\text { Total mesophilic } \\
\text { bacteria }\end{array}$ & $\begin{array}{c}\text { Pathogenic } \\
\text { and/or spoilage }\end{array}$ & $\begin{array}{l}2 \%(w / v) \text { nanochitosan }>2 \%(w / v) \\
\text { chitosan }\end{array}$ & $\begin{array}{c}7.0 \log \mathrm{CFU} / \mathrm{g} \text { for } \\
\text { TMC }\end{array}$ & See section TPC & See section TPC & \multirow{3}{*}{ [49] } \\
\hline & & & & Total psychrotrophic & $\begin{array}{c}\text { Pathogenic } \\
\text { and/or spoilage }\end{array}$ & Idem section TMC & $7.0 \log \mathrm{CFU} / \mathrm{g}$ for & $\begin{array}{c}\text { Uncoated } \\
\text { control-up to } 6\end{array}$ & $\begin{array}{l}2 \%(w / v) \text { chitosan-up to } \\
9 \text { days }\end{array}$ & \\
\hline & $\begin{array}{c}\text { Coating based on } \\
2 \%(w / v) \\
\text { nanochitosan and } \\
\text { glycerol }\end{array}$ & & & & & & & $\begin{array}{l}\text { days } \% \text { glacial } \\
\text { acetic acid-up to } \\
6 \text { days }\end{array}$ & $\begin{array}{c}2 \%(w / v) \\
\text { nanochitosan-up to } 12 \\
\text { days }\end{array}$ & \\
\hline
\end{tabular}


Table 1. Cont.

\begin{tabular}{|c|c|c|c|c|c|c|c|c|c|c|}
\hline \multirow{2}{*}{$\begin{array}{c}\text { Tested Fish } \\
\text { Product }\end{array}$} & \multicolumn{2}{|c|}{ Antimicrobial Packaging Materials } & \multirow{2}{*}{$\begin{array}{c}\text { Storage } \\
\text { Conditions }\end{array}$} & \multirow{2}{*}{$\begin{array}{l}\text { Targeted } \\
\text { Microorganism/ } \\
\text { Group }\end{array}$} & \multirow{2}{*}{$\begin{array}{c}\text { Type of } \\
\text { Microorganism }\end{array}$} & \multirow{2}{*}{$\begin{array}{l}\text { Level of Effectiveness against Targeted } \\
\text { Microorganisms/Group at the End of } \\
\text { Monitoring Time }\end{array}$} & \multirow{2}{*}{$\begin{array}{l}\text { MAL for Targeted } \\
\text { Microorganism/ } \\
\text { Group }\end{array}$} & \multicolumn{2}{|c|}{ Shelf-life of Fish Product } & \multirow{2}{*}{ Ref. } \\
\hline & Film/Coating & $\begin{array}{l}\text { Active Agent/ } \\
\text { Concentration }\end{array}$ & & & & & & Uncoated & Treated & \\
\hline \multirow{5}{*}{$\begin{array}{l}\text { Grass carp } \\
\text { fillets }\end{array}$} & \multirow{5}{*}{$\begin{array}{l}\text { Coating based on } \\
2 \%(w / v) \text { chitosan, } \\
\text { acetic acid, and } \\
\text { glycerol }\end{array}$} & \multirow{5}{*}{\begin{tabular}{|c|} 
Glycerol \\
monolaurate $/ 0.1 \%$ \\
and $0.3 \%$
\end{tabular}} & \multirow{5}{*}{$\begin{array}{l}4^{\circ} \mathrm{C} / 20 \\
\text { days }\end{array}$} & Pseudomonas spp. & Spoilage & $\begin{array}{c}0.3 \% \text { glycerol monolaurate }>0.1 \% \text { glycerol } \\
\text { monolaurate }>\text { control }\end{array}$ & - & See section TVC & See section TVC & \multirow{5}{*}{32} \\
\hline & & & & $\mathrm{H}_{2} \mathrm{~S}$ producing bacteria & Spoilage & Idem section Pseudomonas spp. & - & See section TVC & See section TVC & \\
\hline & & & & Total viable organisms & $\begin{array}{l}\text { Pathogenic } \\
\text { and/or spoilage }\end{array}$ & Idem section Pseudomonas spp. & $\begin{array}{c}7.0 \log \mathrm{CFU} / \mathrm{g} \text { for } \\
\text { TVC }\end{array}$ & $\begin{array}{l}\text { Uncoated } \\
\text { control-up to } 7 \\
\text { days }\end{array}$ & $\begin{array}{c}\text { Control-up to } 15 \text { days } \\
0.1 \% \text { glycerol } \\
\text { monolaurate-up to } 15 \\
\text { days }\end{array}$ & \\
\hline & & & & & & & & & $\begin{array}{c}0.3 \% \text { glycerol } \\
\text { monolaurate-up to } 20 \\
\text { days } \\
\end{array}$ & \\
\hline & & & & $\begin{array}{c}\text { Total psychrotrophic } \\
\text { bacteria }\end{array}$ & $\begin{array}{c}\text { Pathogenic } \\
\text { and/or spoilage }\end{array}$ & Idem section Pseudomonas spp. & - & See section TVC & See section TVC & \\
\hline \multirow[t]{2}{*}{$\begin{array}{l}\text { Beluga } \\
\text { sturgeon } \\
\text { fillets }\end{array}$} & \multirow{2}{*}{$\begin{array}{l}\text { Coating based on } \\
8 \%(w / v) \text { whey } \\
\text { protein concentrate, } \\
\text { glycerol, and Tween } \\
80\end{array}$} & \multirow[t]{2}{*}{$\begin{array}{l}\text { Cinnamon } \\
\mathrm{EO} / 1.5 \%(v / v)\end{array}$} & \multirow[t]{2}{*}{$\begin{array}{l}4{ }^{\circ} \mathrm{C} / 20 \\
\text { days }\end{array}$} & Total viable organisms & $\begin{array}{l}\text { Pathogenic } \\
\text { and/or spoilage }\end{array}$ & $1.5 \%(v / v)$ cinnamon $\mathrm{EO}>$ control & $\begin{array}{c}7.0 \log \mathrm{CFU} / \mathrm{g} \text { for } \\
\text { TVC }\end{array}$ & $\begin{array}{l}\text { Uncoated } \\
\text { control-up to } 4 \\
\text { days }\end{array}$ & $\begin{array}{c}\text { Control-up to } 4 \text { days } \\
1.5 \%(v / v) \text { cinnamon } \\
\text { EO-up to } 16 \text { days } \\
\text { See section TVC }\end{array}$ & \multirow[t]{2}{*}{45} \\
\hline & & & & $\begin{array}{l}\text { Total psychrotrophic } \\
\text { bacteria }\end{array}$ & $\begin{array}{c}\text { Pathogenic } \\
\text { and/or spoilage }\end{array}$ & Idem section TVC & - & See section TVC & See section TVC & \\
\hline \multirow{4}{*}{$\begin{array}{c}\text { Salmon } \\
\text { fillets }\end{array}$} & \begin{tabular}{|c|} 
Coating based on \\
$1 \%(w / w)$ chitosan, \\
acetic acid, and \\
glycerol \\
\end{tabular} & \multirow[t]{2}{*}{-} & \multirow[t]{2}{*}{$2{ }^{\circ} \mathrm{C} / 6$ days } & $\begin{array}{l}\text { Total mesophilic } \\
\text { bacteria }\end{array}$ & $\begin{array}{l}\text { Pathogenic } \\
\text { and/or spoilage }\end{array}$ & $\begin{array}{c}1 \%(w / w) \text { chitosan }>1 \%(w / w) \text { chitosan } \\
\text { and } 2 \%(w / w) \text { tapioca starch }\end{array}$ & - & Not specified & $\begin{array}{l}\text { All treated samples-up } \\
\text { to } 6 \text { days }\end{array}$ & \multirow[t]{2}{*}{ [48] } \\
\hline & \begin{tabular}{|c|} 
Coating based on \\
$1 \%(w / w)$ chitosan, \\
acetic acid, glycerol,, \\
and $2 \%(w / w)$ \\
tapioca starch \\
\end{tabular} & & & $\begin{array}{l}\text { Total psychrotrophic } \\
\text { bacteria }\end{array}$ & $\begin{array}{l}\text { Pathogenic } \\
\text { and/or spoilage }\end{array}$ & Idem section TMC & - & See section TMC & See section TMC & \\
\hline & $\begin{array}{c}\text { Film based on } 8 \% \\
(w / v) \\
\text { gelatin/chitosan, } \\
\text { 3:1, sorbitol and } \\
\text { glycerol }\end{array}$ & $\begin{array}{c}\text { Clove } \mathrm{EO} / 7.5 \% \\
(v / w)\end{array}$ & $\begin{array}{l}2{ }^{\circ} \mathrm{C} / 11 \\
\text { days }\end{array}$ & Total viable organisms & $\begin{array}{l}\text { Pathogenic } \\
\text { and/or spoilage }\end{array}$ & $7.5 \%(v / w)$ clove EO & - & $\begin{array}{l}\text { Uncoated } \\
\text { control-up to } 9 \\
\text { days }\end{array}$ & $\begin{array}{l}7.5 \%(v / w) \text { clove EO-up } \\
\text { to } 11 \text { days }\end{array}$ & [39] \\
\hline & \begin{tabular}{|c} 
Coating based on \\
$1.0,1.5$, and $2 \%$ \\
$(w / v)$ chitosan, \\
lactic acid solution, \\
and Tween 80 \\
\end{tabular} & - & $\begin{array}{l}0{ }^{\circ} \mathrm{C} / 18 \\
\text { days }\end{array}$ & Total viable organisms & $\begin{array}{l}\text { Pathogenic } \\
\text { and/or spoilage }\end{array}$ & $1 \%, 1.5 \%$, and $2 \%(w / v)$ chitosan & $\begin{array}{c}7.0 \log \mathrm{CFU} / \mathrm{g} \text { for } \\
\text { TVC }\end{array}$ & $\begin{array}{l}\text { Uncoated } \\
\text { control-up to } 9 \\
\text { days }\end{array}$ & $\begin{array}{l}\text { All treated samples-up } \\
\text { to } 15 \text { days }\end{array}$ & [46] \\
\hline
\end{tabular}


Table 1. Cont

\begin{tabular}{|c|c|c|c|c|c|c|c|c|c|c|}
\hline \multirow{2}{*}{$\begin{array}{l}\text { Tested Fish } \\
\text { Product }\end{array}$} & \multicolumn{2}{|c|}{ Antimicrobial Packaging Materials } & \multirow{2}{*}{$\begin{array}{c}\text { Storage } \\
\text { Conditions }\end{array}$} & \multirow{2}{*}{$\begin{array}{l}\text { Targeted } \\
\text { Microorganism/ } \\
\text { Group }\end{array}$} & \multirow{2}{*}{$\begin{array}{c}\text { Type of } \\
\text { Microorganism }\end{array}$} & \multirow{2}{*}{$\begin{array}{l}\text { Level of Effectiveness against Targeted } \\
\text { Microorganisms/Group at the End of } \\
\text { Monitoring Time }\end{array}$} & \multirow{2}{*}{$\begin{array}{l}\text { MAL for Targeted } \\
\text { Microorganism/ } \\
\text { Group }\end{array}$} & \multicolumn{2}{|c|}{ Shelf-life of Fish Product } & \multirow[b]{2}{*}{ Ref. } \\
\hline & Film/Coating & $\begin{array}{l}\text { Active Agent/ } \\
\text { Concentration }\end{array}$ & & & & & & Uncoated & Treated & \\
\hline \multirow{9}{*}{$\begin{array}{l}\text { Pike-perch } \\
\text { fillets }\end{array}$} & \multirow[t]{2}{*}{$\begin{array}{c}\text { Coating based on } \\
10 \%(w / v) \text { whey } \\
\text { protein isolate, } \\
\text { glycerol, and Tween } \\
80\end{array}$} & \multirow[t]{2}{*}{$\begin{array}{c}\text { Lactoperoxidase } / 2.5 \% \\
(v / v)\end{array}$} & \multirow{9}{*}{$\begin{array}{l}4^{\circ} \mathrm{C} / 16 \\
\text { days }\end{array}$} & Pseudomonas fluorescens & Spoilage & $\begin{array}{c}2.5 \%(v / v) \text { lactoperoxidase }>2.5 \%(v / v) \\
\text { lactoperoxidase and } 1.5 \%(v / v) \\
\alpha \text {-tocopherol }>2.5 \%(v / v) \text { lactoperoxidase } \\
\text { and } 3 \%(v / v) \alpha \text {-tocopherol }>3 \%(v / v) \\
\alpha-\text { tocopherol }>1.5 \%(v / v) \alpha \text {-tocopherol }> \\
10 \%(w / v) \text { whey protein isolate }>10 \% \\
(w / v) \text { whey protein isolate and } 3 \%(v / v) \\
\text { ethanol }\end{array}$ & - & See section TVC & See section TVC & \multirow{9}{*}{ [33] } \\
\hline & & & & $\mathrm{H}_{2} \mathrm{~S}$ producing bacteria & Spoilage & Idem section Pseudomonas fluorescens & - & See section TVC & $\begin{array}{l}\text { See section TVC } \\
\text { Control.unto } 4\end{array}$ & \\
\hline & \multirow{7}{*}{$\begin{array}{l}\text { Coating based on } \\
10 \%(w / v) \text { whey } \\
\text { protein isolate, } \\
\text { glycerol, ethanol, } \\
\text { and Tween } 80\end{array}$} & \multirow{7}{*}{$\begin{array}{c}\alpha \text {-Tocopherol } / 1.5 \% \\
(v / v) \\
\alpha \text {-Tocopherol/3\% } \\
(v / v) \\
\text { Lactoperoxidase and } \\
\alpha \text {-tocopherol } / 2.5 \% \\
(v / v) \text { and } 1.5 \%(v / v) \\
\text { Lactoperoxidase and } \\
\alpha \text {-tocopherol/2.5\% } \\
(v / v) \text { and } 3 \%(v / v)\end{array}$} & & \multirow[t]{6}{*}{ Total viable organisms } & \multirow[t]{6}{*}{$\begin{array}{l}\text { Pathogenic } \\
\text { and/or spoilage }\end{array}$} & \multirow{6}{*}{$\begin{array}{c}2.5 \%(v / v) \text { lactoperoxidase }>2.5 \%(v / v) \\
\text { lactoperoxidase and } 1.5 \%(v / v) \\
\alpha \text {-tocopherol }>2.5 \%(v / v) \text { lactoperoxidase } \\
\text { and } 3 \%(v / v) \alpha \text {-tocopherol }>3 \%(v / v) \\
\alpha \text { tocopherol }>1.5 \%(v / v) \alpha \text {-tocopherol }> \\
\text { control for coating with lactoperoxidase } \\
>\text { control for other coatings }\end{array}$} & \multirow[t]{6}{*}{$\begin{array}{c}7.0 \log \mathrm{CFU} / \mathrm{g} \text { for } \\
\text { TVC }\end{array}$} & - & $\begin{array}{c}\text { Control-up to } 4 \\
\text { days } \\
2.5 \%(v / v) \\
\text { lactoperoxidase-up } \\
\text { to } 12 \text { days } \\
\end{array}$ & \\
\hline & & & & & & & & & $\begin{array}{c}\text { Control-up to } 4 \\
\text { days }\end{array}$ & \\
\hline & & & & & & & & - & $\begin{array}{c}1.5 \%(v / v) \\
\alpha \text {-tocopherol-up to } \\
\text { 4 days }\end{array}$ & \\
\hline & & & & & & & & & $\begin{array}{c}3 \%(v / v) \\
\alpha \text {-tocopherol-up to } \\
4 \text { days }\end{array}$ & \\
\hline & & & & & & & & & $\begin{array}{c}2.5 \%(v / v) \\
\text { lactoperoxidase and } \\
1.5 \%(v / v) \\
\alpha \text {-tocopherol-up to } \\
12 \text { days } \\
\end{array}$ & \\
\hline & & & & & & & & & $\begin{array}{c}2.5 \%(v / v) \\
\text { lactoperoxidase and } \\
3 \%(v / v) \\
\alpha \text {-tocopherol-up to } \\
8 \text { days }\end{array}$ & \\
\hline & & & & $\begin{array}{c}\text { Total psychrotrophic } \\
\text { bacteria }\end{array}$ & $\begin{array}{l}\text { Pathogenic } \\
\text { and/or spoilage }\end{array}$ & Idem section TVC & $\begin{array}{c}7.0 \log \mathrm{CFU} / \mathrm{g} \text { for } \\
\text { TPC }\end{array}$ & See section TVC & See section TVC & \\
\hline \multirow{2}{*}{$\begin{array}{c}\text { Japanese sea } \\
\text { bass fillets }\end{array}$} & \multirow{2}{*}{$\begin{array}{l}\text { Coating based on } \\
1.5 \%(w / v) \text { chitosan } \\
\text { and acetic acid }\end{array}$} & \multirow{2}{*}{$\begin{array}{c}\text { Citric acid } / 0.5 \%(w / v) \\
\text { Licorice extract } / 1 \% \\
(w / v)\end{array}$} & \multirow{2}{*}{$\begin{array}{l}4^{\circ} \mathrm{C} / 12 \\
\text { days }\end{array}$} & \multirow{2}{*}{ Total viable organisms } & \multirow{2}{*}{$\begin{array}{l}\text { Pathogenic } \\
\text { and/or spoilage }\end{array}$} & \multirow{2}{*}{$\begin{array}{c}0.5 \%(w / v) \text { citric acid }>1 \%(w / v) \text { licorice } \\
\text { extract }>\text { control }\end{array}$} & \multirow{2}{*}{$\begin{array}{c}6.0 \log \mathrm{CFU} / \mathrm{g} \text { for } \\
\text { TVC }\end{array}$} & \multirow{2}{*}{$\begin{array}{l}\text { Uncoated } \\
\text { control-up to } 8 \\
\text { days }\end{array}$} & $\begin{array}{c}\text { Control-up to } 8 \\
\text { days }\end{array}$ & \multirow{2}{*}{ [44] } \\
\hline & & & & & & & & & $\begin{array}{c}0.5 \%(w / v) \text { citric } \\
\text { acid-up to } 12 \text { days } \\
1 \% \text { licorice } \\
\text { extract-up to } 12 \\
\text { days } \\
\end{array}$ & \\
\hline \multirow[t]{2}{*}{$\begin{array}{l}\text { Red drum } \\
\text { fillets }\end{array}$} & \multirow{2}{*}{$\begin{array}{l}\text { Coating based on } \\
1.5 \% \text { chitosan, acetic } \\
\text { acid, and glycerol }\end{array}$} & \multirow{2}{*}{$\begin{array}{c}\text { Grape seed } \\
\text { extract } / 0.2 \%(w / v) \\
\text { Tea polyphenols } / 0.2 \% \\
(w / v)\end{array}$} & \multirow[t]{2}{*}{$\begin{array}{l}4^{\circ} \mathrm{C} / 20 \\
\text { days }\end{array}$} & \multirow[t]{2}{*}{ Total viable organisms } & \multirow[t]{2}{*}{$\begin{array}{l}\text { Pathogenic } \\
\text { and/or spoilage }\end{array}$} & $\begin{array}{l}0.2 \%(w / v) \text { tea polyphenols }>0.2 \%(w / v) \\
\text { grape seed extract }\end{array}$ & $\begin{array}{c}7.0 \log \mathrm{CFU} / \mathrm{g} \text { for } \\
\text { TVC }\end{array}$ & $\begin{array}{l}\text { Uncoated } \\
\text { control-up to } 8\end{array}$ & $\begin{array}{l}0.2 \%(w / v) \text { grape } \\
\text { seed extract-up to } \\
16 \text { days }\end{array}$ & [43] \\
\hline & & & & & & & & & $\begin{array}{l}0.2 \%(w / v) \text { tea } \\
\text { polyphenols-up to } \\
16 \text { days }\end{array}$ & \\
\hline
\end{tabular}


Table 1. Cont.

\begin{tabular}{|c|c|c|c|c|c|c|c|c|c|c|}
\hline \multirow{2}{*}{$\begin{array}{l}\text { Tested } \\
\text { Fish } \\
\text { Product }\end{array}$} & \multicolumn{2}{|c|}{ Antimicrobial Packaging Materials } & \multirow{2}{*}{$\begin{array}{c}\text { Storage } \\
\text { Conditions }\end{array}$} & \multirow{2}{*}{$\begin{array}{l}\text { Targeted } \\
\text { Microorganism/ } \\
\text { Group }\end{array}$} & \multirow{2}{*}{$\begin{array}{c}\text { Type of } \\
\text { Microorganism }\end{array}$} & \multirow{2}{*}{$\begin{array}{l}\text { Level of Effectiveness against Targeted } \\
\text { Microorganisms/Group at the End of Monitoring } \\
\text { Time }\end{array}$} & \multirow{2}{*}{$\begin{array}{l}\text { MAL for Targeted } \\
\text { Microorganism/ } \\
\text { Group }\end{array}$} & \multicolumn{2}{|c|}{ Shelf-life of Fish Product } & \multirow{2}{*}{ Ref. } \\
\hline & Film/Coating & $\begin{array}{l}\text { Active Agent/ } \\
\text { Concentration }\end{array}$ & & & & & & Uncoated & Treated & \\
\hline \multirow{2}{*}{$\begin{array}{l}\text { Golden } \\
\text { pomfret } \\
\text { fillets }\end{array}$} & \multirow{2}{*}{$\begin{array}{l}\text { Coating based on } \\
0.4 \%(w / w) \text { chitosan } \\
\text { Coating based on } \\
0.4 \%(w / w) \text { chitosan } \\
\text { and gelatin }\end{array}$} & \multirow[t]{2}{*}{ 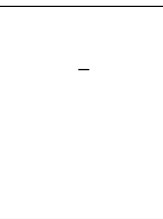 } & \multirow[t]{2}{*}{$\begin{array}{l}4^{\circ} \mathrm{C} / 17 \\
\text { days }\end{array}$} & Total viable organisms & $\begin{array}{l}\text { Pathogenic } \\
\text { and/or spoilage }\end{array}$ & $\begin{array}{c}0.4 \%(w / w) \text { chitosan }=0.4 \%(w / w) \text { chitosan and } \\
3.6 \%(w / w) \text { gelatin }=0.4 \%(w / w) \text { chitosan and } 5.4 \% \\
(w / w) \text { gelatin }=0.4 \%(w / w) \text { chitosan and } 7.2 \% \\
(w / w) \text { gelatin }\end{array}$ & $\begin{array}{c}6.0 \log \mathrm{CFU} / \mathrm{g} \text { for } \\
\text { TVC }\end{array}$ & $\begin{array}{l}\text { Deionized water-up } \\
\text { to } 17 \text { days }\end{array}$ & $\begin{array}{l}\text { All treated } \\
\text { samples-up to } 17 \\
\text { days }\end{array}$ & \multirow[t]{2}{*}{ [47] } \\
\hline & & & & Total yeasts and moulds & $\begin{array}{l}\text { Pathogenic } \\
\text { and/or spoilage }\end{array}$ & $\begin{array}{c}0.4 \%(w / w) \text { chitosan and } 3.6 \%(w / w) \text { gelatin }>0.4 \% \\
(w / w) \text { chitosan and } 5.4 \%(w / w) \text { gelatin }>0.4 \% \\
(w / w) \text { chitosan and } 7.2 \%(w / w) \text { gelatin }>0.4 \% \\
(w / w) \text { chitosan }\end{array}$ & - & See section TVC & See section TVC & \\
\hline \multirow{19}{*}{$\begin{array}{l}\text { Hake } \\
\text { fillets }\end{array}$} & \multirow{19}{*}{$\begin{array}{l}\text { Coating based on } \\
10 \%(w / w) \text { whey } \\
\text { protein isolate and } \\
\text { glycerol }\end{array}$} & \multirow{13}{*}{$\begin{array}{c}\text { Oregano } \\
\text { EO/1\% and } \\
3 \%(w / w) \\
\text { Thyme EO/1\% } \\
\text { and } 3 \%(w / w)\end{array}$} & \multirow{5}{*}{$\begin{array}{l}4^{\circ} \mathrm{C} / 8 \\
\text { days }\end{array}$} & Total viable organisms & $\begin{array}{c}\text { Pathogenic } \\
\text { and/or spoilage }\end{array}$ & $\begin{array}{c}3 \%(w / w) \text { thyme } \mathrm{EO}>1 \%(w / w) \text { thyme } \mathrm{EO}>3 \% \\
(w / w) \text { oregano } \mathrm{EO}>1 \%(w / w) \text { oregano } \mathrm{EO}> \\
\text { control }\end{array}$ & $\begin{array}{l}7.0 \log \mathrm{CFU} / \mathrm{g} \text { for } \\
\text { TVC }\end{array}$ & $\begin{array}{l}\text { Uncoated control-up } \\
\text { to } 4 \text { days }\end{array}$ & $\begin{array}{l}\text { All treated } \\
\text { samples-up to } 4 \\
\text { days }\end{array}$ & \multirow{19}{*}{ [34] } \\
\hline & & & & $\begin{array}{l}\text { Total psychrotrophic } \\
\text { bacteria }\end{array}$ & $\begin{array}{c}\text { Pathogenic } \\
\text { and/or spoilage }\end{array}$ & Idem section TVC & $\begin{array}{c}7.0 \log \mathrm{CFU} / \mathrm{g} \text { for } \\
\text { TPC }\end{array}$ & See section TVC & See section TVC & \\
\hline & & & & Enterobacteriaceae & $\begin{array}{l}\text { Pathogenic } \\
\text { and/or spoilage }\end{array}$ & $\begin{array}{l}3 \%(w / w) \text { oregano } \mathrm{EO}>3 \%(w / w) \text { thyme } \mathrm{EO}>1 \% \\
(w / w) \text { thyme } \mathrm{EO}>1 \%(w / w) \text { oregano } \mathrm{EO}>\text { control }\end{array}$ & $\begin{array}{l}4.0 \log \mathrm{CFU} / \mathrm{g} \text { for } \\
\text { Enterobacteriaceae }\end{array}$ & See section TVC & See section TVC & \\
\hline & & & & $\begin{array}{c}\text { Lactic acid bacteria } \\
\mathrm{H}_{2} \mathrm{~S} \text { producing bacteria }\end{array}$ & $\begin{array}{l}\text { Spoilage } \\
\text { Spoilage }\end{array}$ & Idem section Enterobacteriaceae & - & See section TVC & See section TVC & \\
\hline & & & & $\begin{array}{l}\mathrm{H}_{2} \mathrm{~S} \text { producing bacteria } \\
\text { Pseudomonas spp. }\end{array}$ & $\begin{array}{l}\text { Spoilage } \\
\text { Spilase }\end{array}$ & Idem section TVC & - & See section TVC & See section TVC & \\
\hline & & & \multirow{8}{*}{$\begin{array}{l}4{ }^{\circ} \mathrm{C} \text { under } \\
\text { MAP } \\
\text { conditions/ } \\
16 \text { days }\end{array}$} & \multirow{3}{*}{ Total viable organisms } & \multirow{3}{*}{$\begin{array}{l}\text { Pathogenic } \\
\text { and/or spoilage }\end{array}$} & \multirow{3}{*}{$\begin{array}{l}3 \%(w / w) \text { thyme } \mathrm{EO}>3 \%(w / w) \text { oregano } \mathrm{EO}>1 \% \\
(w / w) \text { thyme } \mathrm{EO}>1 \%(w / w) \text { oregano } \mathrm{EO}>\text { control }\end{array}$} & \multirow{3}{*}{$\begin{array}{c}7.0 \log \mathrm{CFU} / \mathrm{g} \text { for } \\
\mathrm{TVC}\end{array}$} & \multirow{3}{*}{$\begin{array}{l}\text { Uncoated control-up } \\
\text { to } 8 \text { day }\end{array}$} & $\begin{array}{l}\text { See section TVC } \\
\begin{array}{c}\text { Control-up to } 8 \\
\text { days }\end{array}\end{array}$ & \\
\hline & & & & & & & & & $\begin{array}{l}3 \%(w / w) \text { oregano } \\
\text { EO-up to } 16 \text { days }\end{array}$ & \\
\hline & & & & & & & & & $\begin{array}{l}\text { 1\% }(w / w) \text { oregano } \\
\text { EO-up to } 8 \text { days } \\
3 \%(w / w) \text { thyme } \\
\text { EO-up to } 16 \text { days } \\
1 \%(w / w) \text { thyme } \\
\text { EO-up to } 16 \text { days }\end{array}$ & \\
\hline & & & & $\begin{array}{l}\text { Total psychrotrophic } \\
\text { bacteria }\end{array}$ & $\begin{array}{c}\text { Pathogenic } \\
\text { and/or spoilage }\end{array}$ & $\begin{array}{l}3 \%(w / w) \text { oregano } \mathrm{EO}>1 \%(w / w) \text { thyme } \mathrm{EO}>3 \% \\
(w / w) \text { thyme } \mathrm{EO}>1 \%(w / w) \text { oregano } \mathrm{EO}>\text { control }\end{array}$ & $\begin{array}{c}7.0 \log \mathrm{CFU} / \mathrm{g} \text { for } \\
\text { TPC }\end{array}$ & See section TVC & See section TVC & \\
\hline & & & & Enterobacteriaceae & $\begin{array}{l}\text { Pathogenic } \\
\text { and/or spoilage }\end{array}$ & $\begin{array}{l}3 \%(w / w) \text { oregano } \mathrm{EO}>3 \%(w / w) \text { thyme } \mathrm{EO}>1 \% \\
(w / w) \text { thyme } \mathrm{EO}>1 \%(w / w) \text { oregano } \mathrm{EO}>\text { control }\end{array}$ & $\begin{array}{l}4.0 \log \mathrm{CFU} / \mathrm{g} \text { for } \\
\text { Enterobacteriaceae }\end{array}$ & See section TVC & See section TVC & \\
\hline & & & & Lactic acid bacteria & Spoilage & $\begin{array}{l}3 \%(w / w) \text { oregano } \mathrm{EO}>3 \%(w / w) \text { thyme } \mathrm{EO}>1 \% \\
(w / w) \text { oregano } \mathrm{EO}>1 \%(w / w) \text { thyme } \mathrm{EO}>\text { control }\end{array}$ & - & See section TVC & See section TVC & \\
\hline & & & & $\mathrm{H}_{2} \mathrm{~S}$ producing bacteria & Spoilage & Idem section LAB & - & See section TVC & See section TVC & \\
\hline & & & & Pseudomonas spp. & Spoilage & $\begin{array}{l}1 \%(w / w) \text { thyme } \mathrm{EO}>3 \%(w / w) \text { oregano } \mathrm{EO}>1 \% \\
(w / w) \text { oregano } \mathrm{EO}>3 \%(w / w) \text { thyme } \mathrm{EO}>\text { control }\end{array}$ & - & See section TVC & See section TVC & \\
\hline & & \multirow{6}{*}{$\begin{array}{l}\text { Oregano } \\
\mathrm{EO} / 1 \% \text { and } \\
3 \%(w / w)\end{array}$} & \multirow{6}{*}{$\begin{array}{l}4{ }^{\circ} \mathrm{C} \text { under } \\
\text { air and } \\
\text { MAP } \\
\text { conditions/ } \\
12 \text { days }\end{array}$} & \multirow[t]{2}{*}{ Total viable organisms } & \multirow[t]{2}{*}{$\begin{array}{l}\text { Pathogenic } \\
\text { and/or spoilage }\end{array}$} & \multirow[t]{2}{*}{$\begin{array}{c}3 \%(w / w) \text { oregano } \mathrm{EO}(\mathrm{MAP})>3 \%(w / w) \text { oregano } \\
\mathrm{EO}(\mathrm{air})\end{array}$} & \multirow[t]{2}{*}{$\begin{array}{c}7.0 \log \mathrm{CFU} / \mathrm{g} \text { for } \\
\mathrm{TVC}\end{array}$} & \multirow{2}{*}{$\begin{array}{l}\text { Uncoated control } \\
\quad \text { (air)-up to } 4 \\
\text { daysUncoated } \\
\text { (MAP)-up to } 4 \text { days }\end{array}$} & $\begin{array}{l}3 \%(w / w) \text { oregano } \\
\text { EO (MAP)-up to } 12 \\
\text { days }\end{array}$ & \\
\hline & & & & & & & & & $\begin{array}{l}3 \%(w / w) \text { oregano } \\
\text { EO (air)-up to } 4 \\
\text { days }\end{array}$ & \\
\hline & & & & $\begin{array}{l}\text { Total psychrotrophic } \\
\text { bacteria }\end{array}$ & $\begin{array}{c}\text { Pathogenic } \\
\text { and/or spoilage }\end{array}$ & Idem section TVC & $\begin{array}{c}7.0 \log \text { CFU/g for } \\
\text { TVC }\end{array}$ & See section TVC & See section TVC & \\
\hline & & & & Enterobacteriaceae & $\begin{array}{l}\text { Pathogenic } \\
\text { and/or spoilage }\end{array}$ & $\begin{array}{c}3 \%(w / w) \text { oregano } \mathrm{EO}(\mathrm{MAP})>3 \%(w / w) \text { oregano } \\
\mathrm{EO}(\mathrm{air})\end{array}$ & $\begin{array}{l}4.0 \log \mathrm{CFU} / \mathrm{g} \text { for } \\
\text { Enterobacteriaceae }\end{array}$ & See section TVC & See section TVC & \\
\hline & & & & $\begin{array}{l}\text { Lactic acid bacteria } \\
\text { H.S producin } \text { baterian }^{2}\end{array}$ & $\begin{array}{l}\text { Spoilage } \\
\text { Spoilage }\end{array}$ & Idem section Enterobacteriaceae & - & See section TVC & See section TVC & \\
\hline & & & & $\begin{array}{l}\mathrm{H}_{2} \mathrm{~S} \text { producing bacteria } \\
\text { Pseudomonas spp. }\end{array}$ & $\begin{array}{l}\text { Spoilage } \\
\text { Spoilage } \\
\end{array}$ & $\begin{array}{l}\text { Idem section Enterobacteriaceae } \\
\text { Idem section Enterobacteriaceae }\end{array}$ & - & $\begin{array}{l}\text { See section TVC } \\
\text { See section TVC }\end{array}$ & $\begin{array}{r}\text { See section TVC } \\
\text { See section TVC }\end{array}$ & \\
\hline
\end{tabular}

EO, essential oil; CFU, colony-forming units; TVC, total viable count; TMC, total mesophilic bacteria; TPC, total psychrotrophic bacteria; LAB, Lactic Acid Bacteria; MAL, maximum acceptable level. 


\subsection{Efficacy of Edible Films/Coatings on Enhancing the Shelf-Life of Fresh Fish}

The application of above-mentioned edible films and coatings to fish fillets resulted in an extension of their shelf-life as compared to uncoated controls. The film based on $1 \%$ quince seed mucilage incorporated with $2 \%$ thyme EO prolonged the shelf-life of rainbow trout fillets by 12 days [28] and the one based on $3 \%$ gelatin and $1.5 \%$ alginate incorporating $1.5 \%$ oregano EO by 6 days [29]; the coating based on $2 \%$ chitosan incorporated with $1.5 \%$ cinnamon $\mathrm{EO}$ by 8 days [42], the one based on $1 \%$ carrageenan incorporated with $1 \%$ lemon EO by 12 days [30], and the one based on $8 \%$ whey protein concentrate/glycerol, 2:1 by 6 days [31]. In these cases, the shelf-life was stated considering a maximum acceptable level of $7.0 \log \mathrm{CFU} / \mathrm{g}$ for the total viable count.

Shelf-lives of silver carp and grass carp fillets were extended by 6 and 13 days, respectively, when coatings based on $2 \%$ nanochitosan [49] and $2 \%$ chitosan incorporated with $0.3 \%$ glycerol monolaurate [32] was used.

When applied to salmon fillets, the film based on $8 \%$ gelatin/chitosan, 3:1 incorporated with $7.5 \%$ clove EO [39] and coatings based on 1\%, 1.5\%, and 2\% chitosan [46] enhanced the shelf-lives by 6 days.

On beluga sturgeon fillets, the coating based on $8 \%$ whey protein concentrate incorporated with $1.5 \%$ cinnamon EO [45] extended the shelf-life by 12 days.

The study of Shokri \& Ehsani (2017) [33] on pike-perch fillets show a shelf-life prolongation by 8 days when a packaging material based on $10 \%$ whey protein isolate incorporated with $2.5 \%$ lactoperoxidase was used for coating.

Another study, carried out by Qiu et al. (2014) [44], has shown an increased storage stability (from 8 to 12 days) of Japanese sea bass fillets coated with a solution containing $1.5 \%$ chitosan and $0.5 \%$ citric acid [44].

The coating formulation of Li et al. (2013) [43], also based on 1.5\% chitosan but incorporated with $0.2 \%$ tea polyphenols, prolonged the microbiological shelf-life of red drum fillets by 8 days.

In a study on hake fillets, Carrión-Granda et al. (2018) [34] reported a shelf-life prolongation by 8 days when a coating based on $10 \%$ whey protein isolate incorporated with $3 \%$ oregano EO was used under MAP conditions.

Our review also revealed some studies in the existing literature focused on the application of synthetic films to fresh fish fillets. Cardoso et al. (2017) [50] have tested the efficiency of films based on poly(butylene adipate-co-terephthalate) incorporated with different levels of oregano EO $(2.5 \%$, $5.0 \%, 7.5 \%$, and $10 \%$ ) in lessening coliform bacteria, Staphylococcus aureus, and total psychrotrophic bacteria in fish fillets. The film incorporated with $10 \%(w / w)$ oregano EO showed the highest inhibitory effect on all bacteria leading to a shelf-life extension of 6 days for wrapped samples. The shelf-life was established considering a maximum acceptable level of $5.0 \mathrm{log}$ CFU/g for Staphylococcus aureus.

In another study, Rollini et al. (2016) [51] have evaluated the efficacy of film based on polyethylene terephthalate coated with $3 \%(w / v)$ lysozyme and lactoferrin water solution, respectively, coextruded multilayer film based on polypropylene incorporated with $4.8 \%$ carvacrol against total mesophilic bacteria, total psychrotrophic bacteria, Enterobacteriaceae (including coliform bacteria), lactic acid bacteria, Pseudomonas spp., and $\mathrm{H}_{2} \mathrm{~S}$ producing bacteria. The film that was coated with $3 \%$ lysozyme-lactoferrin has shown the best antibacterial results on total mesophilic bacteria, total psychrotrophic bacteria, lactic acid bacteria, and $\mathrm{H}_{2} \mathrm{~S}$ producing bacteria, but the one incorporated with $4.8 \%$ carvacrol on Enterobacteriaceae (including coliform bacteria) and Pseudomonas spp. All of the samples were stored for up to four days; therefore, no extension of shelf-life was possible to notice for treated samples in such a short period of storage.

At high levels of incorporation with EOs, active films/coatings may impart foreign flavours to the products on which are applied. Of all the studies that are mentioned in Table 1, only two mentioned their effects on the sensory attributes of fresh fish. The study of Jouki et al. (2014) [28] revealed no significant negative effect of films based on $1 \%$ quince seed mucilage incorporated with oregano and thyme EOs in concentrations of up to $2 \%$ on the organoleptic acceptability of rainbow trout fillets. 
Similar observations were also reported by Ojagh et al. (2010) [42] when a coating based on $2 \%$ chitosan incorporated with $1.5 \%$ cinnamon EO treatment was applied.

\subsection{Effects of Edible Films/Coatings on the Chemical Quality of Fresh Fish}

Table 2 summarizes the effects of the above-mentioned edible films and coatings on the chemical quality of fresh fish. Chemical indicators of lipid oxidation (TBARS-thiobarbituric acid reactive substances), degradation of nitrogen-containing compounds (TVB-N-total volatile basic nitrogen and TMA-N-trimethylamine nitrogen), and adenosine triphosphate breakdown ( $k$-value) were measured during storage of fish fillets.

The thiobarbituric acid reactive substances (TBARS) assay is commonly used to evaluate malondialdehyde (MDA) content. MDA is one of the most significant products of lipid damage [52]. Several researchers $[28,33,42]$ have proposed maximum permitted levels for TBARS although the threshold criteria have not yet received regulatory approval; values $<3 \mathrm{mg} \mathrm{MDA} / \mathrm{kg}$ for perfect quality material, $3 \leq \mathrm{MDA} / \mathrm{kg}<5$ for good quality material, and $5 \leq \mathrm{MDA} / \mathrm{kg}<8$ for suitable for human consumption. In the published data reviewed in the current paper, TBARS values ranged from 0.2 to $0.9 \mathrm{mg} \mathrm{MDA} / \mathrm{kg}$ for rainbow trout fillets, 3.0 to $4.0 \mathrm{mg}$ MDA $/ \mathrm{kg}$ for silver carp fillets, 0.9 to $1.2 \mathrm{mg}$ $\mathrm{MDA} / \mathrm{kg}$ for grass carp fillets, 0.06 to $0.12 \mathrm{mg} \mathrm{MDA} / \mathrm{kg}$ for beluga sturgeon fillets, 1.1 to $1.8 \mathrm{mg}$ MDA $/ \mathrm{kg}$ for salmon fillets, 1.0 to $2.5 \mathrm{mg} \mathrm{MDA} / \mathrm{kg}$ for pike-perch fillets, 0.2 to $2.0 \mathrm{mg} \mathrm{MDA} / \mathrm{kg}$ for Japanese sea bass fillets, and 0.8 to $1.8 \mathrm{mg} \mathrm{MDA} / \mathrm{kg}$ for red drum fillets; samples meeting the requirements for good quality material, respectively perfect quality material.

Total volatile base nitrogen (TVB-N) is one of the most widely used fish spoilage indicator [53]. It represents the sum of ammonia, methylamine, dimethylamine, trimethylamine, and other basic nitrogenous volatile compounds resulted from fish degradation $[54,55]$. Commission Regulation (EC) 2074/2005 [56] set limits for TVB-N only for redfish, flatfish, Atlantic salmon, hake, and gadoids; values $\leq 25 \mathrm{mg} \mathrm{N} / 100 \mathrm{~g}$ for Sebastes spp., Helicolenus dactylopterus, and Sebastichthys capensis, $\leq 30 \mathrm{mg}$ N/100 g for species belonging to the Pleuronectidae family (with the exception of halibut: Hippoglossus spp.), and $\leq 35 \mathrm{mg} \mathrm{N} / 100 \mathrm{~g}$ for Salmo salar, species belonging to the Merlucciidae family, and species belonging to the Gadidae family. Since no limits of acceptability for rainbow trout, grass carp, beluga sturgeon, pike-perch, Japanese sea bass, and red drum have been established by EC Regulation 2074/2005 [56], the values that were reported previously in the literature were taken as threshold limits by Ojagh et al. (2010) [42], Jouki et al. (2014) [28], Kazemi \& Rezaei (2015) [29], Volpe et al. (2015) [30], Yıldız \& Yangilar (2016) [31], Yu et al. (2017) [32], Bahram et al. (2016) [45], Shokri and Ehsani (2017) [33], Qiu et al. (2014) [44], and Li et al. (2013) [43]; levels of 25-35 mg N/100 g for rainbow trout, $\leq 15 \mathrm{mg}$ N/100 for grass carp, levels of 35-40 mg N/100 g for beluga sturgeon, $\leq 35 \mathrm{mg} \mathrm{N} / 100$ for pike-perch, levels of 30-35 mg N/100 g for Japanese sea bass, and $\leq 25 \mathrm{mg} \mathrm{N} / 100$ for red drum. TVB-N values reported in the reviewed studies ranged from 10 to $65 \mathrm{mg} \mathrm{N} / 100 \mathrm{~g}$ for rainbow trout fillets, 44 to $60 \mathrm{mg}$ $\mathrm{N} / 100 \mathrm{~g}$ for silver carp fillets, 15 to $28 \mathrm{mg} \mathrm{N} / 100 \mathrm{~g}$ for grass carp fillets, 50 to $70 \mathrm{mg} \mathrm{N} / 100 \mathrm{~g}$ for beluga sturgeon fillets, 28 to $33 \mathrm{mg} \mathrm{N} / 100 \mathrm{~g}$ for salmon fillets, 35 to $45 \mathrm{mg} \mathrm{N} / 100 \mathrm{~g}$ for pike-perch fillets, 30 to $100 \mathrm{mg} \mathrm{N} / 100 \mathrm{~g}$ for Japanese sea bass fillets, 34 to $51 \mathrm{mg} \mathrm{N} / 100 \mathrm{~g}$ for red drum fillets, and 11 to $94 \mathrm{mg}$ $\mathrm{N} / 100 \mathrm{~g}$ for golden pomfret fillets.

Most marine fish contain TMAO [57]. TMAO is also found, with few exceptions, in freshwater fish, but only in small concentrations [58]. Certain bacteria that occur naturally on the skin, in the guts of fish, and in water can break down TMAO to TMA. The amount of trimethylamine nitrogen (TMA-N) produced is a measure of the activity of spoilage bacteria in the flesh and so is an indicator of the degree of spoilage [57]. There are no regulatory limits available for TMA level in fish. The rejection limit proposed by Jouki et al. (2014) [28] was $<5 \mathrm{mg} \mathrm{N} / 100 \mathrm{~g}$ and by Souza et al. (2010) [46] $\leq 5 \mathrm{mg}$ $\mathrm{N} / 100 \mathrm{~g}$. 
Table 2. Effects of antimicrobial packaging on chemical quality of fresh fish.

\begin{tabular}{|c|c|c|c|c|c|c|c|c|c|c|c|c|}
\hline \multirow{2}{*}{$\begin{array}{l}\text { Tested } \\
\text { Fish } \\
\text { Product }\end{array}$} & \multicolumn{2}{|c|}{ Antimicrobial Packaging Materials } & \multirow{2}{*}{$\begin{array}{c}\text { Storage } \\
\text { Conditions }\end{array}$} & \multirow{2}{*}{$\begin{array}{c}\text { ML Obtained for } \\
\text { TBARS during Storage }\end{array}$} & \multirow{2}{*}{ TLV for TBA } & \multirow{2}{*}{$\begin{array}{l}\text { ML Obtained for TVB-N } \\
\text { during Storage }\end{array}$} & \multirow{2}{*}{$\begin{array}{l}\text { TLV for } \\
\text { TVB-N }\end{array}$} & \multirow{2}{*}{$\begin{array}{c}\text { ML Obtained for } \\
\text { TMA-N during Storage }\end{array}$} & \multirow{2}{*}{$\begin{array}{l}\text { TLV for } \\
\text { TMA-N }\end{array}$} & \multirow{2}{*}{$\begin{array}{l}\text { MLObtained for } \\
\text { K-Value during } \\
\text { Storage }\end{array}$} & \multirow{2}{*}{$\begin{array}{c}\text { TL for } \\
K \text {-Value }\end{array}$} & \multirow{2}{*}{ Ref. } \\
\hline & Film/Coating & $\begin{array}{l}\text { Active Agent/ } \\
\text { Concentration }\end{array}$ & & & & & & & & & & \\
\hline \multirow{5}{*}{$\begin{array}{l}\text { Rainbow } \\
\text { trout } \\
\text { fillets }\end{array}$} & $\begin{array}{l}\text { Coating based on } 2 \% \\
(w / v) \text { chitosan, acetic } \\
\text { acid, and glycerol }\end{array}$ & $\begin{array}{c}\text { Cinnamon } \\
\mathrm{EO} / 1.5 \% \\
(v / v)\end{array}$ & $\begin{array}{c}4 \\
{ }^{\circ} \mathrm{C} / 16 \text { days }\end{array}$ & $\begin{array}{c}1.5 \%(v / v) \text { cinnamon EO } \\
(\sim 0.2 \mathrm{mg} \text { MDA } / \mathrm{kg})< \\
\text { uncoated control (below } \\
0.25 \mathrm{mg} \text { MDA } / \mathrm{kg})< \\
\text { control (below } 0.25 \mathrm{mg} \\
\mathrm{MDA} / \mathrm{kg})\end{array}$ & $\begin{array}{c}5 \mathrm{mg} \\
\text { MDA/kg-good } \\
\text { quality; } 8 \mathrm{mg} \\
\text { MDA } / \mathrm{kg} \text {-suitable } \\
\text { for human } \\
\text { consumption }\end{array}$ & $\begin{array}{c}1.5 \%(v / v) \text { cinnamon EO } \\
(\sim 10 \mathrm{mg} \mathrm{N} / 100 \mathrm{~g})<\text { control } \\
(\sim 20 \mathrm{mg} \mathrm{N} / 100 \mathrm{~g})< \\
\text { uncoated control } \\
(\sim 40 \mathrm{mg} \mathrm{N} / 100 \mathrm{~g}) \\
\end{array}$ & $\begin{array}{l}25 \mathrm{mg} \\
\mathrm{N} / 100 \mathrm{~g}\end{array}$ & - & - & - & - & [42] \\
\hline & $\begin{array}{l}\text { Film based on } 1 \% \\
(w / w) \text { quince seed } \\
\text { mucilage, glycerol, } \\
\text { and Tween } 80\end{array}$ & $\begin{array}{c}\text { Oregano } \\
\mathrm{EO} / 1 \%, 1.5 \%, \\
\text { and } 2 \%(v / v) \\
\text { Thyme } \\
\mathrm{EO} / 1 \%, 1.5 \%, \\
\text { and } 2 \%(v / v)\end{array}$ & $\begin{array}{l}4^{\circ} \mathrm{C} / 18 \\
\text { days }\end{array}$ & $\begin{array}{c}2 \%(v / v) \text { oregano EO } \\
(\sim 0.4 \mathrm{mg} \mathrm{MDA} / \mathrm{kg})< \\
1.5 \%(v / v) \text { oregano EO } \\
(\sim 0.4 \mathrm{mg} \mathrm{MDA} / \mathrm{kg})<\% \\
(v / v) \text { thyme EO }(\text { below } \\
0.5 \mathrm{mg} \mathrm{MDA} / \mathrm{kg})<1 \% \\
(v / v) \text { oregano EO }(\text { below } \\
0.5 \mathrm{mg} \mathrm{MDA} / \mathrm{kg})<1.5 \\
(v / v) \text { thyme EO }(\mathrm{below} \\
0.6 \mathrm{mg} \mathrm{MDA} / \mathrm{kg})<1 \% \\
(v / v) \text { thyme EO }(\mathrm{below} \\
0.6 \mathrm{mg} \mathrm{MDA} / \mathrm{kg})< \\
\text { control }(\sim 0.8 \mathrm{mg} \\
\mathrm{MDA} / \mathrm{kg})<\text { uncoated } \\
\text { control }(\sim 0.9 \mathrm{mg} \\
\mathrm{MDA} / \mathrm{kg})\end{array}$ & $\begin{array}{l}\text { below } 5 \mathrm{mg} \\
\mathrm{MDA} / \mathrm{kg}\end{array}$ & 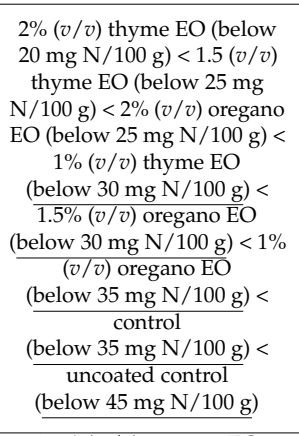 & $\begin{array}{l}25 \mathrm{mg} \\
\mathrm{N} / 100 \mathrm{~g}\end{array}$ & $\begin{array}{c}2 \%(v / v) \text { thyme EO } \\
(\sim 5 \mathrm{mg} \mathrm{N} / 100 \mathrm{~g})<1.5 \% \\
(v / v) \text { thyme } \mathrm{EO} \\
(\sim 6 \mathrm{mg} \mathrm{N} / 100 \mathrm{~g})<2 \% \\
\frac{(v / v) \text { oregano } \mathrm{EO}}{(\sim 6 \mathrm{mg} \mathrm{N} / 100 \mathrm{~g})<1 \%} \\
\frac{(v / v) \text { thyme } \mathrm{EO}}{(\text { below } 8 \mathrm{mg} \mathrm{N} / 100 \mathrm{~g})<} \\
1.5 \%(v / v) \text { oregano EO } \\
(\text { below } 8 \mathrm{mg} \mathrm{N} / 100 \mathrm{~g})< \\
1 \%(v / v) \text { oregano EO } \\
(\sim 8 \mathrm{mg} \mathrm{N} / 100 \mathrm{~g})< \\
\text { uncoated control } \\
\frac{(12 \mathrm{mg} \mathrm{N} / 100 \mathrm{~g})<}{\text { control }}< \\
(\sim 12 \mathrm{mg} \mathrm{N} / 100 \mathrm{~g}) \\
\end{array}$ & $\begin{array}{c}\text { below } 5 \\
\mathrm{mg} \mathrm{N} / 100 \\
\mathrm{~g}\end{array}$ & - & - & [28] \\
\hline & $\begin{array}{c}\text { Film based on } 3 \% \\
(w / v) \text { gelatin and } \\
1.5 \%(w / v) \text { alginate, } \\
\text { glycerol, and Tween } \\
80 \\
\end{array}$ & $\begin{array}{l}\text { Oregano } \\
\mathrm{EO} / 1.5 \% \\
(w / v)\end{array}$ & $\begin{array}{l}4{ }^{\circ} \mathrm{C} / 15 \\
\text { days }\end{array}$ & - & - & $\begin{array}{c}1.5 \%(w / v) \text { oregano EO } \\
(\sim 60 \mathrm{mg} \mathrm{N} / 100 \mathrm{~g})<\text { control } \\
(\sim 65 \mathrm{mg} \mathrm{N} / 100 \mathrm{~g})< \\
\text { uncoated control } \\
(\sim 65 \mathrm{mg} \mathrm{N} / 100 \mathrm{~g}) \\
\end{array}$ & $\begin{array}{l}35 \mathrm{mg} \\
\mathrm{N} / 100 \mathrm{~g}\end{array}$ & - & - & - & - & [29] \\
\hline & $\begin{array}{l}\text { Coating based on } 1 \% \\
(w / w) \text { carrageenan }\end{array}$ & $\begin{array}{c}\text { Lemon } \\
\mathrm{EO} / 1 \%(w / w)\end{array}$ & $\begin{array}{l}4{ }^{\circ} \mathrm{C} / 15 \\
\text { days }\end{array}$ & - & - & $\begin{array}{c}1 \%(w / w) \text { lemon EO }(20 \mathrm{mg} \\
\mathrm{N} / 100 \mathrm{~g})<\text { control } \\
\text { (below } 35 \mathrm{mg} \mathrm{N} / 100 \mathrm{~g})< \\
\begin{array}{c}\text { uncoated control } \\
(40 \mathrm{mg} \mathrm{N} / 100 \mathrm{~g})\end{array}\end{array}$ & $\begin{array}{l}25 \mathrm{mg} \\
\mathrm{N} / 100 \mathrm{~g}\end{array}$ & - & - & - & - & [30] \\
\hline & $\begin{array}{c}\text { Coating based on } 8 \% \\
(w / w) \text { whey protein } \\
\text { concentrate } \\
\text { Coating based on } 8 \% \\
(w / w) \text { why protein } \\
\text { concentrate/glycerol, } \\
1: 1 \text { and } 2: 1\end{array}$ & - & $\begin{array}{l}4{ }^{\circ} \mathrm{C} / 15 \\
\text { days }\end{array}$ & $\begin{array}{c}8 \%(w / w) \text { whey protein } \\
\text { concentrate/glycerol, } 2: 1 \\
(0.4 \mathrm{mg} \mathrm{MDA} / \mathrm{kg})<8 \% \\
(w / w) \text { whey protein } \\
\text { concentrate } / \text { glycerol, } 1: 1 \\
(0.5 \mathrm{mg} \mathrm{MDA} / \mathrm{kg})<8 \% \\
(w / w) \text { whey protein } \\
\text { concentrate }(0.6 \mathrm{mg} \\
\mathrm{MDA} / \mathrm{kg})<\text { uncoated } \\
\text { control }(0.7 \mathrm{mg} \\
\mathrm{MDA} / \mathrm{kg})\end{array}$ & - & $\begin{array}{c}8 \%(\bar{w} / w) \text { whey protein } \\
\text { concentrate/glycerol, } 2: 1 \\
(21.1 \mathrm{mg} \mathrm{N} / 100 \mathrm{~g})<8 \% \\
(w / w) \text { whey protein } \\
\text { concentrate/glycerol, } 1: 1 \\
(24.6 \mathrm{mg} \mathrm{N} / 100 \mathrm{~g})<8 \% \\
(w / w) \text { whey protein } \\
\text { concentrate } \\
(27.4 \mathrm{mg} \mathrm{N} / 100 \mathrm{~g})< \\
\text { uncoated control } \\
(32.5 \mathrm{mg} \mathrm{N} / 100 \mathrm{~g})\end{array}$ & $\begin{array}{l}25 \mathrm{mg} \\
\mathrm{N} / 100 \mathrm{~g}\end{array}$ & - & - & - & - & [31] \\
\hline
\end{tabular}


Table 2. Cont

\begin{tabular}{|c|c|c|c|c|c|c|c|c|c|c|c|c|}
\hline \multirow{2}{*}{$\begin{array}{l}\text { Tested } \\
\text { Fish } \\
\text { Product }\end{array}$} & \multicolumn{2}{|c|}{ Antimicrobial Packaging Materials } & \multirow{2}{*}{$\begin{array}{c}\text { Storage } \\
\text { Conditions }\end{array}$} & \multirow{2}{*}{$\begin{array}{l}\text { ML Obtained for TBARS } \\
\text { during Storage }\end{array}$} & \multirow{2}{*}{ TLV for TBA } & \multirow{2}{*}{$\begin{array}{l}\text { ML Obtained for TVB-N } \\
\text { during Storage }\end{array}$} & \multirow{2}{*}{$\begin{array}{l}\text { TLV for } \\
\text { TVB-N }\end{array}$} & \multirow{2}{*}{$\begin{array}{l}\text { MLObtained for } \\
\text { TMA-N during } \\
\text { Storage }\end{array}$} & \multirow{2}{*}{$\begin{array}{l}\text { TLV for } \\
\text { TMA-N }\end{array}$} & \multirow{2}{*}{$\begin{array}{l}\text { MLObtained for } \\
K \text { KValue during } \\
\text { Storage }\end{array}$} & \multirow{2}{*}{$\begin{array}{c}\text { TL for } \\
K \text {-Value }\end{array}$} & \multirow{2}{*}{ Ref. } \\
\hline & Film/Coating & $\begin{array}{l}\text { Active Agent/ } \\
\text { Concentration }\end{array}$ & & & & & & & & & & \\
\hline $\begin{array}{c}\text { Silver } \\
\text { carp fillets }\end{array}$ & $\begin{array}{c}\text { Coating based on } 2 \% \\
(w / v) \text { chitosan and } \\
\text { glycerolCoating } \\
\text { based on } 2 \%(w / v) \\
\text { nanochitosan and } \\
\text { glycerol } \\
\end{array}$ & - & $\begin{array}{c}4^{\circ} \mathrm{C} / 12 \\
\text { days }\end{array}$ & $\begin{array}{c}2 \%(w / v) \text { chitosan (below } 3 \\
\mathrm{mg} \mathrm{MDA} / \mathrm{kg})<2 \%(w / v) \\
\text { nanochitosan (below } 3 \mathrm{mg} \\
\mathrm{MDA} / \mathrm{kg})<\text { uncoated } \\
\text { control }(\text { below } 4 \mathrm{mg} \\
\mathrm{MDA} / \mathrm{kg})<1 \% \text { glacial acetic } \\
\text { acid }(\sim 4 \mathrm{mg} \text { MDA } / \mathrm{kg})\end{array}$ & - & $\begin{array}{c}2 \%(w / v) \text { nanochitosan }(44.4 \\
\mathrm{mg} \mathrm{N} / 100 \mathrm{~g})<2 \%(w / v) \\
\text { chitosan }(30.8 \mathrm{mg} \mathrm{N} / 100 \mathrm{~g})< \\
1 \% \text { glacial acetic acid }(\text { below } \\
60 \mathrm{mg} \mathrm{N} / 100 \mathrm{~g})<\text { uncoated } \\
\text { control }(\sim 60 \mathrm{mg} \mathrm{N} / 100 \mathrm{~g})\end{array}$ & - & - & - & - & - & [49] \\
\hline $\begin{array}{l}\text { Grass carp } \\
\text { fillets }\end{array}$ & $\begin{array}{c}\text { Coating based on } 2 \% \\
(w / v) \text { chitosan, acetic } \\
\text { acid, and glycerol }\end{array}$ & $\begin{array}{c}\text { Glycerol } \\
\text { monolaurate/ } \\
0.1 \% \text { and } 0.3 \%\end{array}$ & $\begin{array}{c}4{ }^{\circ} \mathrm{C} / \\
20 \text { days }\end{array}$ & $\begin{array}{c}0.3 \% \text { glycerol monolaurate } \\
(\sim 09 \mathrm{mg} \text { MDA } / \mathrm{kg})<0.1 \% \\
\text { glycerol monolaurate }(\sim 0.9 \\
\mathrm{mg} \mathrm{MDA} / \mathrm{kg})<\text { o ontrol }(0.9 \\
\mathrm{mg} \mathrm{MDA} / \mathrm{gg})<\text { uncoated } \\
\text { control }(\mathrm{below} 1.2 \mathrm{mg} \\
\mathrm{MDA} / \mathrm{kg})\end{array}$ & - & $\begin{array}{c}0.3 \% \text { glycerol monolaurate } \\
(15 \mathrm{mg} \mathrm{N} / 100 \mathrm{~g})<0.1 \% \\
\text { glycerol monolaurate } \\
\text { (below 20 mg N/100 g) } \\
\text { control }(\sim 22.5 \mathrm{mg} \mathrm{N} / 100 \mathrm{~g}) \\
\quad<\text { uncoated control } \\
(\sim 27.5 \mathrm{mg} \mathrm{N} / 100 \mathrm{~g}) \\
\end{array}$ & $\begin{array}{l}15 \mathrm{mg} \\
\mathrm{N} / 100 \mathrm{~g}\end{array}$ & - & - & $\begin{array}{c}0.3 \% \text { glycerol } \\
\text { monolaurate } \\
(\underline{\sim 69 \%)}<0.1 \% \\
\text { glycerol } \\
\text { monolaurate } \\
(77.7 \%)<\text { control } \\
(78.2 \%)< \\
\text { uncoated control } \\
(\underline{90.5 \%)})\end{array}$ & $\begin{array}{l}<20 \% \text {-vf; } \\
<60 \% \text {-mf; } \\
>60 \% \text {-rp }\end{array}$ & [32] \\
\hline $\begin{array}{l}\text { Beluga } \\
\text { sturgeon } \\
\text { fillets }\end{array}$ & $\begin{array}{c}\text { Coating based on } 8 \% \\
(w / v) \text { whey protein } \\
\text { concentrate, glycerol, } \\
\text { and Tween } 80\end{array}$ & $\begin{array}{l}\text { Cinnamon } \\
\mathrm{EO} / 1.5 \%(v / v)\end{array}$ & $\begin{array}{l}4 \%{ }^{\circ} \mathrm{C} / \\
20 \text { days }\end{array}$ & $\begin{array}{c}1.5 \%(v / v) \text { cinnamon EO } \\
\text { (below } 0.06 \mathrm{mg} \mathrm{MDA} / \mathrm{kg})< \\
\text { control (below } 0.1 \mathrm{mg} \\
\mathrm{MDA} / \mathrm{kg})<\text { uncoated } \\
\text { control (below } 0.12 \mathrm{mg} \\
\mathrm{MDA} / \mathrm{kg} \text { ) }\end{array}$ & - & 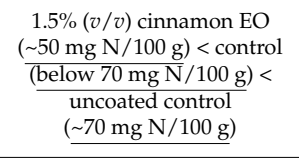 & $\begin{array}{l}35-40 \mathrm{mg} \\
\mathrm{N} / 100 \mathrm{~g}\end{array}$ & - & - & - & - & [45] \\
\hline $\begin{array}{l}\text { Salmon } \\
\text { fillets }\end{array}$ & $\begin{array}{c}\text { Coating based on } \\
1.0 \%, 1.5 \% \text {, and } 2 \% \\
(w / v) \text { chitosan, lactic } \\
\text { acid solution, and } \\
\text { Tween } 80 \\
\end{array}$ & - & $\begin{array}{c}0{ }^{\circ} \mathrm{C} / \\
18 \text { days }\end{array}$ & $\begin{array}{l}\text { All treated samples } \\
(1.1 \mathrm{mg} \text { MDA } / \mathrm{kg})< \\
\text { uncoated control } \\
(1.8 \mathrm{mg} \text { MDA } / \mathrm{kg}) \\
\end{array}$ & $1 \mathrm{mg} \mathrm{MDA} / \mathrm{kg}$ & $\begin{array}{c}\text { All treated samples }(28 \mathrm{mg} \\
\mathrm{N} / 100 \mathrm{~g})<\text { uncoated control } \\
(33 \mathrm{mg} \mathrm{N} / 100 \mathrm{~g})\end{array}$ & $\begin{array}{c}30 \mathrm{mg} \\
\text { TVB-N/100 } \\
\mathrm{g}\end{array}$ & $\begin{array}{c}\text { All treated samples } \\
(5 \mathrm{mg} \mathrm{N} / 100 \mathrm{~g})< \\
\text { uncoated control } \\
(6 \mathrm{mg} \mathrm{N} / 100 \mathrm{~g}) \\
\end{array}$ & $\begin{array}{l}5 \mathrm{mg} \\
\mathrm{N} / 100 \mathrm{~g}\end{array}$ & $\begin{array}{c}\text { All treated } \\
\text { samples }(\underline{46 \%})< \\
\text { uncoated control } \\
(\underline{50 \%})\end{array}$ & $40 \%$ & [46] \\
\hline \multirow[t]{2}{*}{$\begin{array}{l}\text { Pike-perch } \\
\text { fillets }\end{array}$} & $\begin{array}{c}\text { Coating based on } \\
10 \%(w / v) \text { whey } \\
\text { protein isolate, } \\
\text { glycerol, and Tween } \\
80 \\
\end{array}$ & $\begin{array}{c}\text { Lactoperoxidase/ } \\
2.5 \%(v / v)\end{array}$ & \multirow[t]{2}{*}{$\begin{array}{l}4{ }^{\circ} \mathrm{C} / \\
16 \text { days }\end{array}$} & \multirow[b]{2}{*}{$\begin{array}{c}3 \%(v / v) \alpha \text {-tocopherol } \\
\text { (below } 1 \mathrm{mg} \mathrm{MDA} / \mathrm{kg})< \\
2.5 \%(v / v) \text { lactoperoxidase } \\
\text { and } 3 \%(v / v) \alpha \text {-tocopherol } \\
\text { (below } 1 \mathrm{mg} \mathrm{MDA} / \mathrm{kg})< \\
1.5 \%(v / v) \alpha \text {-tocopherol }(\sim 1 \\
\mathrm{mg} \mathrm{MDA} / \mathrm{kg})<2.5 \%(v / v) \\
\mathrm{lactoperoxidase} \text { and } 1.5 \% \\
(v / v) \alpha \text {-tocopherol }(\sim 1 \mathrm{mg} \\
\mathrm{MDA} / \mathrm{kg})<\text { control for other } \\
\text { coatings (below } 2.5 \mathrm{mg} \\
\mathrm{MDA} / \mathrm{kg})<\text { control for } \\
\text { coating with lactoperoxidase } \\
\text { (below } 2.5 \mathrm{mg} \mathrm{MDA} / \mathrm{kg})< \\
2.5 \%(v / v) \text { lactoperoxidase } \\
(\sim 2.5 \mathrm{mg} \mathrm{MDA} / \mathrm{kg})\end{array}$} & \multirow{2}{*}{$\begin{array}{c}\text { below } 3 \mathrm{mg} \\
\mathrm{MDA} / \mathrm{kg} \text {-perfect } \\
\text { quality material; } \\
\text { below } 5 \mathrm{mg} \\
\text { MDA } / \mathrm{kg} \text {-good } \\
\text { quality material }\end{array}$} & \multirow[b]{2}{*}{$\begin{array}{c}2.5 \%(v / v) \text { lactoperoxidase } \\
\text { (below } 35 \mathrm{mg} \mathrm{N} / 100 \mathrm{~g})< \\
2.5 \%(v / v) \text { lactoperoxidase } \\
\text { and } 1.5 \%(v / v) \alpha \text {-tocopherol } \\
(\text { below } 40 \mathrm{mg} \mathrm{N} / 100 \mathrm{~g})< \\
\text { control for coating with } \\
\text { lactoperoxidase } \\
(\sim 40 \mathrm{mg} \mathrm{N} / 100 \mathrm{~g})<\text { control } \\
\text { for other coatingl } \\
(\sim 40 \mathrm{mg} \mathrm{N} / 100 \mathrm{~g})<3 \% \\
(v / v) \alpha \text {-tocopherol } \\
\text { (below } 45 \mathrm{mg} \mathrm{N} / 10 \mathrm{~g})< \\
1.5 \%(v / v) \alpha \text {-tocopherol } \\
\text { (below } 45 \mathrm{mg} \mathrm{N} / 100 \mathrm{~g})< \\
2.5 \%(v / v) \text { lactoperoxidase } \\
\text { and } 3 \%(v / v) \alpha \text {-tocopherol } \\
\text { (below } 45 \mathrm{mg} \mathrm{N} / 100 \mathrm{~g})\end{array}$} & \multirow[t]{2}{*}{$\begin{array}{l}35 \mathrm{mg} \\
\mathrm{N} / 100 \mathrm{~g}\end{array}$} & \multirow[t]{2}{*}{-} & \multirow[t]{2}{*}{-} & \multirow[t]{2}{*}{-} & \multirow[t]{2}{*}{-} & \multirow[t]{2}{*}{ [33] } \\
\hline & $\begin{array}{c}\text { Coating based on } \\
10 \%(w / v) \text { whey } \\
\text { protein isolate, } \\
\text { glycerol, ethanol, and } \\
\text { Tween } 80\end{array}$ & $\begin{array}{c}\alpha \text {-Tocopherol/ } \\
1.5 \%(v / v) \\
\alpha \text {-Tocopherol/ } \\
3 \%(v / v) \\
\text { Lactoperoxidase } \\
\text { and } \\
\alpha \text {-tocopherol/ } \\
2.5 \%(v / v) \\
\text { and } 1.5 \%(v / v) \\
\text { Lactoperoxidase } \\
\text { and } \\
\alpha \text {-tocopherol/ } \\
2.5 \%(v / v) \text { and } \\
3 \%(v / v) \\
\end{array}$ & & & & & & & & & & \\
\hline
\end{tabular}


Table 2. Cont.

\begin{tabular}{|c|c|c|c|c|c|c|c|c|c|c|c|c|}
\hline \multirow{2}{*}{$\begin{array}{l}\text { Tested } \\
\text { Fish } \\
\text { Product }\end{array}$} & \multicolumn{2}{|c|}{ Antimicrobial Packaging Materials } & \multirow{2}{*}{$\begin{array}{c}\text { Storage } \\
\text { Conditions }\end{array}$} & \multirow{2}{*}{$\begin{array}{l}\text { ML Obtained for TBARS } \\
\text { during Storage }\end{array}$} & \multirow{2}{*}{ TLV for TBA } & \multirow{2}{*}{$\begin{array}{l}\text { ML Obtained for TVB-N } \\
\text { during Storage }\end{array}$} & \multirow{2}{*}{$\begin{array}{l}\text { TLV for } \\
\text { TVB-N }\end{array}$} & \multirow{2}{*}{$\begin{array}{c}\text { ML Obtained for } \\
\text { TMA-N during Storage }\end{array}$} & \multirow{2}{*}{$\begin{array}{l}\text { TLV for } \\
\text { TMA-N }\end{array}$} & \multirow{2}{*}{$\begin{array}{l}\text { MLObtained for } \\
\text { K-Value during } \\
\text { Storage }\end{array}$} & \multirow{2}{*}{$\begin{array}{c}\text { TL for } \\
K \text {-Value }\end{array}$} & \multirow{2}{*}{ Ref. } \\
\hline & Film/Coating & $\begin{array}{l}\text { Active Agent/ } \\
\text { Concentration }\end{array}$ & & & & & & & & & & \\
\hline $\begin{array}{l}\text { Japanese } \\
\text { sea bass } \\
\text { fillets }\end{array}$ & $\begin{array}{l}\text { Coating based on } \\
1.5 \%(w / v) \text { chitosan } \\
\text { and acetic acid }\end{array}$ & $\begin{array}{c}\text { Citric } \\
\text { acid } / 0.5 \% \\
(w / v) \\
\text { Licorice } \\
\text { extract } / 1 \% \\
(w / v)\end{array}$ & $\begin{array}{l}4{ }^{\circ} \mathrm{C} / \\
12 \text { days }\end{array}$ & $\begin{array}{c}0.5 \%(w / v) \text { citric acid }(\sim 0.2 \\
\mathrm{mg} \mathrm{MDA} / \mathrm{kg})<\%(w / v) \\
\text { licorice extract }(\sim 0.2 \mathrm{mg} \\
\mathrm{MDA} / \mathrm{kg})<\text { control }(\text { below } \\
1.5 \mathrm{mg} \mathrm{MDA} / \mathrm{kg})<\text { uncoated } \\
\text { control (below } 2.0 \mathrm{mg} \\
\mathrm{MDA} / \mathrm{kg})\end{array}$ & - & $\begin{array}{c}0.5 \%(w / v) \text { citric acid }(29.7 \\
\mathrm{mg} \mathrm{N} / 100 \mathrm{~g})<1 \%(w / v) \\
\text { licorice extract } \\
(48.0 \mathrm{mg} \mathrm{N} / 100 \mathrm{~g})<\text { control } \\
\frac{(60.5 \mathrm{mg} \mathrm{N} / 100 \mathrm{~g})<}{\mathrm{uncoated} \mathrm{control}} \\
(100.2 \mathrm{mg} \mathrm{N} / 100 \mathrm{~g})\end{array}$ & $\begin{array}{l}30-35 \mathrm{mg} \\
\mathrm{N} / 100 \mathrm{~g}\end{array}$ & - & - & - & - & [44] \\
\hline $\begin{array}{l}\text { Red } \\
\text { drum } \\
\text { fillets }\end{array}$ & $\begin{array}{l}\text { Coating based on } \\
1.5 \% \text { chitosan, acetic } \\
\text { acid, and glycerol }\end{array}$ & $\begin{array}{c}\text { Grape seed } \\
\text { extract/0.2\% } \\
(w / v) \\
\text { Tea } \\
\text { polyphenols } / 0.2 \\
(w / v)\end{array}$ & $\begin{array}{l}\quad 4^{\circ} \mathrm{C} / 20 \\
\quad \text { days }\end{array}$ & $\begin{array}{c}0.2 \%(w / v) \text { tea polyphenols } \\
(\sim 0.8 \mathrm{mg} \mathrm{MDA} / \mathrm{kg})<0.2 \% \\
(w / v) \text { grape seed extract } \\
(\sim 1.0 \mathrm{mg} \mathrm{MDA} / \mathrm{kg})< \\
\text { uncoated control }(1.8 \mathrm{mg} \\
\mathrm{MDA} / \mathrm{kg})\end{array}$ & - & $\begin{array}{c}0.2 \%(w / v) \text { tea polyphenols } \\
(33.69 \mathrm{mg} \mathrm{N} / 100 \mathrm{~g})<0.2 \% \\
(w / v) \text { grape seed extract } \\
(38.17 \mathrm{mg} \mathrm{N} / 100 \mathrm{~g})< \\
\text { uncoated control } \\
(51.25 \mathrm{mg} \mathrm{N} / 100 \mathrm{~g}) \\
\end{array}$ & $\begin{array}{c}25 \mathrm{mg} \\
\mathrm{N} / 100 \mathrm{~g}\end{array}$ & - & - & $\begin{array}{c}0.2 \%(w / v) \text { tea } \\
\text { polyphenols } \\
(\sim 40 \%)<0.2 \% \\
(w / v) \text { grape seed } \\
\text { extract }(\sim 45 \%)< \\
\text { uncoated control } \\
(62.57 \%)\end{array}$ & $60 \%$ & [43] \\
\hline \multirow[b]{2}{*}{$\begin{array}{l}\text { Golden } \\
\text { pomfret } \\
\text { fillets }\end{array}$} & $\begin{array}{c}\text { Coating based on } \\
0.4 \%(w / w) \text { chitosan } \\
\end{array}$ & \multirow[t]{2}{*}{-} & \multirow[t]{2}{*}{$\begin{array}{l}4{ }^{\circ} \mathrm{C} / \\
17 \text { days }\end{array}$} & \multirow[t]{2}{*}{-} & \multirow[t]{2}{*}{ - } & \multirow{2}{*}{$\begin{array}{c}0.4 \%(w / w) \text { chitosan and } \\
7.2 \%(w / w) \text { gelatin }(10.51 \mathrm{mg} \\
\mathrm{N} / 100 \mathrm{~g})<0.4 \%(w / w) \\
\text { chitosan and } 5.4 \%(w / w) \\
\text { gelatin }(12.31 \mathrm{mg} \mathrm{N} / 100 \mathrm{~g})< \\
0.4 \%(w / w) \text { chitosan and } \\
3.6 \%(w / w) \text { gelatin }(13.48 \mathrm{mg} \\
\mathrm{N} / 100 \mathrm{~g})<\text { deionized water } \\
(93.52 \mathrm{mg} \mathrm{N} / 100 \mathrm{~g})\end{array}$} & \multirow[t]{2}{*}{ - } & \multirow[t]{2}{*}{ - } & \multirow[t]{2}{*}{ - } & \multirow[t]{2}{*}{-} & \multirow[t]{2}{*}{-} & \multirow[t]{2}{*}{ [47] } \\
\hline & $\begin{array}{l}\text { Coating based on } \\
0.4 \%(w / w) \text { chitosan } \\
\text { and gelatin }\end{array}$ & & & & & & & & & & & \\
\hline
\end{tabular}

TBARS, thiobarbituric acid reactive substances; TLV, threshold limit value; ML, maximum levels; TVB-N, total volatile basic nitrogen; TMA-N, trimethylamine nitrogen; MDA, malondialdehyde; $\mathrm{vf}$, very fresh; $\mathrm{mf}$, moderately fresh; rp, rejection point. 
$K$-value is an important chemical index widely used for fish freshness [59]. During post-mortem storage of fish, autolytic changes take place in the muscle that determines adenosine triphosphate (ATP) degradation with the formation of adenosine-5'-diphosphate (ADP), adenosine-5'-monophosphate (AMP), inosine- $5^{\prime}$-monophosphate (IMP), inosine (HxR), and hypoxanthine (Hx). K-value is calculated as the percentage of the sum of HxR and Hx, divided by the sum of ATP, ADP, AMP, IMP, $\mathrm{HxR}$, and Hx [12,59]. Since there are no legally enforceable limits for $k$-value in fish, $\mathrm{Yu}$ et al. (2017) [32] proposed the following freshness criteria: very fresh fish $(k$-value $<20 \%)$, moderately fresh ( $k$-value $<60 \%$ ), and spoiled ( $k$-value $>60 \%$ ). $K$-values reported in the discussed studies ranged from $68.7 \%$ to $90.5 \%$ for grass carp fillets, $46 \%$ to $50 \%$ for salmon fillets and $40 \%$ to $62.6 \%$ for red drum fillets; samples meeting freshness criteria for moderately fresh, respectively spoiled.

\section{Conclusions}

The active packaging of fish represents an economic alternative to conventional preservation technologies (vacuum and modified atmosphere packaging) due to the limited capital investment as compared to those. Besides being biodegradable, edible films and coatings improve the microbiological stability of fish and reduce waste; moreover, retard lipid oxidation. For the past 10 years, research on the use of antimicrobial packaging materials for fresh fish applications has undergone considerable evolution; nevertheless, as far as we know, there is not yet an edible film or coating commercially available on the market.

Fish represent one of the most-traded segments of the world food sector. Therefore, there is a great demand for the packaging of this good. Industrial production and commercialization of antimicrobial packaging materials for fresh fish could be an exploitable sector by the packaging industry. Suppliers of active packaging materials on the European market need to make sure that their products comply with the requirements of Regulations (EC) 1935/2004 [60] and (EC) 450/2009 [61] regarding active and intelligent materials that are intended to come into contact with food, respectively, Regulation (EC) 1333/2008 [62] that lays down specifications for food additives. Additional studies are however needed to further validate these findings, especially on the stability of antimicrobial films/coatings during shipment, storage, and handling.

Author Contributions: Conceptualization, C.A.S. and D.C.V.; Formal Analysis, M.-I.S.; Funding Acquisition, D.C.V.; Methodology, C.A.S. and D.C.V.; Supervision, C.A.S. and D.C.V.; Writing-Original Draft, M.-I.S.; Writing-Review \& Editing, C.A.S. and D.C.V.

Funding: This research was funded by a grant of the Romanian National Authority for Scientific Research and Innovation, CCDI-UEFISCDI, project number 27/2018 CO FUND-MANUNET III-NON-ACT-2, within PNCDI III.

Acknowledgments: We are grateful for the administrative and financial support received from the University of Agricultural Sciences and Veterinary Medicine Cluj-Napoca, Romania.

Conflicts of Interest: The authors declare no conflict of interest.

\section{References}

1. FAO. The State of World Fisheries and Aquaculture 2016: Contributing to Food Security and Nutrition for All; FAO: Rome, Italy, 2016.

2. Watterson, A.; Little, D.; Young, J.A.; Boyd, K.; Azim, E.; Murray, F. Towards integration of environmental and health impact assessments for wild capture fishing and farmed fish with particular reference to public health and occupational health dimensions. Int. J. Environ. Res. Public Health 2008, 5, 258-277. [CrossRef] [PubMed]

3. Gustavsson, J.; Cederberg, C.; Sonesson, U.; van Otterdijk, R.; Meybeck, A. Global Food Losses and Food Waste. Extent, Causes and Prevention; FAO: Rome, Italy, 2011; pp. 10-14.

4. Akande, G.; Diei-Ouadi, Y. Post-Harvest Losses in Small-Scale Fisheries: Case Studies in Five Sub-Saharan African Countries; FAO Fisheries and Aquaculture Technical Paper No. 550; FAO: Rome, Italy, 2010; pp. XI-XIII.

5. Hall, G.M. Fish Processing: Sustainability and New Opportunities; Wiley-Blackwell: Oxford, UK, 2011; pp. 51-76. 
6. Blackburn, C.D.W. Managing microbial food spoilage: an overview. In Food Spoilage Microorganisms, 1st ed.; Blackburn, C.D.W., Ed.; Woodhead Publishing Ltd.: Cambridge, UK, 2006; pp. 147-170.

7. Reducing Post-Harvest Losses. Available online: http://www.oceansatlas.org/subtopic/en/c/1337/ (accessed on 2 August 2018).

8. Makawa, Z.; Kapute, F.; Valeta, J. Effect of delayed processing on nutrient composition, $\mathrm{pH}$ and organoleptic quality of pond raised tilapia (Oreochromis shiranus) stored at ambient temperature. Afr. J. Food Agric. Nutr. Dev. 2014, 14, 8872-8884.

9. Tesfay, S.; Teferi, M. Assessment of fish post-harvest losses in Tekeze dam and Lake Hashenge fishery associations: northern Ethiopia. Agric. Food Secur. 2017, 6, 4. [CrossRef]

10. Calligaris, S.; Manzocco, L. Critical indicators in shelf life assessment. In Shelf Life Assessment of Food; Nicoli, M.C., Ed.; CRC Press/Taylor and Francis Group: Boca Raton, FL, USA, 2012; pp. 61-74.

11. Morrison, C.R. Fish and shellfish. In Frozen Food Technology; Mallet, C.P., Ed.; Blackie Academic \& Professional: Glasgow, UK, 1993; pp. 196-236.

12. Huss, H.H. Quality and Quality Changes in Fresh Fish; FAO Fisheries Technical Paper No. 348; FAO: Rome, Italy, 1995; pp. 35-67.

13. Diei-Ouadi, Y.; Mgawe, Y.I. Post-Harvest Fish Loss Assessment in Small-Scale Fisheries: A Guide for the Extension Officer; FAO Fisheries and Aquaculture Technical Paper No. 559; FAO: Rome, Italy, 2011; pp. 3-11.

14. Reddy, N.R.; Villanueva, M.; Kautter, D.A. Shelf life of modified-atmosphere-packaged fresh tilapia fillets stored under refrigeration and temperature-abuse conditions. J. Food Prot. 1995, 58, 908-914. [CrossRef]

15. Getu, A.; Misganaw, K.; Bazezew, M. Post-harvesting and major related problems of fish production. Fish. Aquac. J. 2015, 6, 4. [CrossRef]

16. Ashie, I.N.A.; Smith, J.P.; Simpson, B.K. Spoilage and shelf-life extension of fresh fish and shellfish. Crit. Rev. Food Sci. Nutr. 1996, 36, 87-121. [CrossRef] [PubMed]

17. Vodnar, D.C.; Pop, O.L.; Dulf, F.V.; Socaciu, C. Antimicrobial efficiency of edible films in food industry. Not. Bot. Horti Agrobo. Cluj-Napoca 2015, 43, 302-312. [CrossRef]

18. Yildirim, S.; Röcker, B.; Pettersen, M.K.; Nilsen-Nygaard, J.; Ayhan, Z.; Rutkaite, R.; Radusin, T.; Suminska, P.; Marcos, B.; Coma, V. Active packaging applications for food. Compr. Rev. Food Sci. Food Saf. 2018, 17, 165-199. [CrossRef]

19. Velu, S.; Abu Bakar, F.; Mahyudin, N.A.; Saari, N.; Zaman, M.Z. Effect of modified atmosphere packaging on microbial flora changes in fishery products. Int. Food Res. J. 2013, 20, 17-26.

20. Cyprian, O.; Lauzon, H.L.; Jóhannsson, R.; Sveinsdóttir, K.; Arason, S.; Martinsdóttir, E. Shelf life of air and modified atmosphere-packaged fresh tilapia (Oreochromis niloticus) fillets stored under chilled and superchilled conditions. Food Sci. Nutr. 2013, 1, 130-140. [CrossRef] [PubMed]

21. Grujić, S.; Grujić, R.; Kovačić, K. Effects of modified atmosphere packaging on quality and safety of fresh meat. Quality of Life (Banja Luka) 2010, 2-4, 121-133. [CrossRef]

22. Rennie, T.J.; Sunjka, P.S. Modified atmosphere for storage, transportation, and packaging. In Novel Postharvest Treatments of Fresh Produce; Pareek, S., Ed.; CRC Press/Taylor and Francis Group: Boca Raton, FL, USA, 2018; pp. 433-480.

23. Boziaris, I.S.; Parlapani, F.F. Specific spoilage organisms (SSOs) in fish. In The Microbiological Quality of Food, 1st ed.; Bevilacqua, A., Corbo, M.R., Sinigaglia, M., Eds.; Woodhead Publishing Ltd.: Cambridge, UK, 2017; pp. 61-98.

24. Gram, L.; Dalgaard, P. Fish spoilage bacteria - problems and solutions. Curr. Opin. Biotechnol. 2002, 13, 262-266. [CrossRef]

25. Gram, L.; Huss, H.H. Microbiological spoilage of fish and fish products. Int. J. Food Microbiol. 1996, 33, 121-127. [CrossRef]

26. Fraser, O.P.; Sumar, S. Compositional changes and spoilage in fish (part II)—Microbiological induced deterioration. Nutr. Food Sci. 1998, 98, 325-329. [CrossRef]

27. Kuuliala, L.; Abatih, E.; Ioannidis, A.-G.; Vanderroost, M.; De Meulenaer, B.; Ragaert, P.; Devlieghere, F. Multivariate statistical analysis for the identification of potential seafood spoilage indicators. Food Control 2018, 84, 49-60. [CrossRef]

28. Jouki, M.; Yazdi, F.T.; Mortazavi, S.A.; Koocheki, A.; Khazaei, N. Effect of quince seed mucilage edible films incorporated with oregano or thyme essential oil on shelf-life extension of refrigerated rainbow trout fillets. Int. J. Food Microbiol. 2014, 174, 88-97. [CrossRef] [PubMed] 
29. Kazemi, S.M.; Rezaei, M. Antimicrobial effectiveness of gelatin-alginate film containing oregano essential oil for fish preservation. J. Food Saf. 2015, 35, 482-490. [CrossRef]

30. Volpe, M.G.; Siano, F.; Paolucci, M.; Sacco, A.; Sorrentino, A.; Malinconico, M.; Varricchio, E. Active edible coating effectiveness in shelf-life enhancement of trout (Oncorhynchusmykiss) fillets. LWT-Food Sci. Technol. 2015, 60, 615-622. [CrossRef]

31. Yıldız, P.O.; Yangilar, F. Effects of different whey protein concentrate coating on selected properties of rainbow trout (Oncorhynchus mykiss) during cold storage $\left(4^{\circ} \mathrm{C}\right)$. Int. J. Food Prop. 2016, 19, 2007-2015. [CrossRef]

32. Yu, D.; Jiang, Q.; Xu, Y.; Xia, W. The shelf life extension of refrigerated grass carp (Ctenopharyngodon idellus) fillets by chitosan coating combined with glycerol monolaurate. Int. J. Biol. Macromol. 2017, 101, 448-454. [CrossRef] [PubMed]

33. Shokri, S.; Ehsani, A. Efficacy of whey protein coating incorporated with lactoperoxidase and $\alpha$-tocopherol in shelf life extension of Pike-Perch fillets during refrigeration. LWT-Food Sci. Technol. 2017, 85, 225-231. [CrossRef]

34. Carrión-Granda, X.; Fernández-Pan, I.; Rovira, J.; Maté, J.I. Effect of antimicrobial edible coatings and modified atmosphere packaging on the microbiological quality of cold stored hake (Merluccius merluccius) fillets. J. Food Qual. 2018. [CrossRef]

35. Semeniuc, C.A.; Socaciu, M.I.; Socaci, S.A.; Mureşan, V.; Fogarasi, M.; Rotar, A.M. Chemometric comparison and classification of some essential oils extracted from plants belonging to Apiaceae and Lamiaceae families based on their chemical composition and biological activities. Molecules 2018, 23, 2261. [CrossRef] [PubMed]

36. Chouhan, S.; Sharma, K.; Guleria, S. Antimicrobial activity of some essential oils-present status and future perspectives. Medicines (Basel) 2017, 8, 5. [CrossRef]

37. Burt, S. Essential oils: Their antibacterial properties and potential applications in foods - a review. Int. J. Food Microbiol. 2004, 94, 223-253. [CrossRef] [PubMed]

38. Kuorwel, K.K.; Cran, M.J.; Sonneveld, K.; Miltz, J.; Bigger, S.W. Essential oils and their principal constituents as antimicrobial agents for synthetic packaging films. J. Food Sci. 2011, 76, R164-R177. [CrossRef] [PubMed]

39. Gómez-Estaca, J.; López de Lacey, A.; Gómez-Guillén, M.C.; López-Caballero, M.E.; Monter, P. Antimicrobial activity of composite edible films based on fish gelatin and chitosan incorporated with clove essential oil. J. Aquat. Food Prod. Technol. 2009, 18, 46-52. [CrossRef]

40. Han, Y.T.; Tammineni, N.; Ünlü, G.; Rasco, B.; Nindo, C. Inhibition of Listeria monocytogenes on rainbow trout (Oncorhynchus mykiss) using trout skin gelatin edible films containing nisin. J. Food Chem. Nutr. 2013, 1, 6-15.

41. Min, B.J.; Oh, J.H. Antimicrobial activity of catfish gelatin coating containing origanum (Thymus capitatus) oil against gram-negative pathogenic bacteria. J. Food Sci. 2009, 74, M143-M148. [CrossRef] [PubMed]

42. Ojagh, S.M.; Rezaei, M.; Rzavi, S.H.; Hosseini, S.M.H. Effect of chitosan coatings enriched with cinnamon oil on the quality of refrigerated rainbow trout. Food Chem. 2010, 1, 193-198. [CrossRef]

43. Li, T.; Li, J.; Hu, W.; Li, X. Quality enhancement in refrigerated red drum (Sciaenops ocellatus) fillets using chitosan coatings containing natural preservatives. Food Chem. 2013, 138, 821-826. [CrossRef] [PubMed]

44. Qiu, X.; Chen, S.; Liu, G.; Yang, Q. Quality enhancement in the Japanese sea bass (Lateolabrax japonicas) fillets stored at $4{ }^{\circ} \mathrm{C}$ by chitosan coating incorporated with citric acid or licorice extract. Food Chem. 2014, 162, 156-160. [CrossRef] [PubMed]

45. Bahram, S.; Rezaie, M.; Soltani, M.; Kamali, A.; Abdollahi, M.; Ahmadabad, M.K.; Nemati, M. Effect of whey protein concentrate coating cinamon oil on quality and shelf life of refrigerated Beluga Sturegeon (Huso huso). J. Food Qual. 2016, 39, 743-749. [CrossRef]

46. Souza, B.W.S.; Cerqueira, M.A.; Ruiz, H.A.; Martins, J.T.; Casariego, A.; Teixeira, J.A.; Vicente, A.A. Effect of chitosan-based coatings on the shelf life of salmon (Salmo salar). J. Agric. Food Chem. 2010, 58, 11456-11462. [CrossRef] [PubMed]

47. Feng, X.; Bansal, N.; Yang, H. Fish gelatin combined with chitosan coating inhibits myofibril degradation of golden pomfret (Trachinotus blochii) fillet during cold storage. Food Chem. 2016, 200, 283-292. [CrossRef] [PubMed]

48. Vásconez, M.B.; Flores, S.K.; Campos, C.A.; Alvarado, J.; Gerschenson, L.N. Antimicrobial activity and physical properties of chitosan-tapioca starch based edible films and coatings. Food Res. Int. 2009, 42, 762-769. [CrossRef] 
49. Ramezani, A.; Zarei, M.; Raminnejad, N. Comparing the effectiveness of chitosan and nanochitosan coatings on the quality of refrigerated silver carp fillets. Food Control 2015, 51, 43-48. [CrossRef]

50. Cardoso, L.G.; Santos, J.C.P.; Camilloto, G.P.; Miranda, A.L.; Druzian, J.I.; Guimarães, A.G. Development of active films poly (butylene adipate co-terephthalate)_PBAT incorporated with oregano essential oil and application in fish fillet preservation. Ind. Crop. Prod. 2017, 108, 388-397. [CrossRef]

51. Rollini, M.; Nielsen, T.; Musatti, A.; Limbo, S.; Piergiovanni, L.; Munoz, P.H.; Gavara, R. Antimicrobial performance of two different packaging materials on the microbiological quality of fresh salmon. Coatings 2016, 6, 6. [CrossRef]

52. Semeniuc, C.A.; Mandrioli, M.; Rodriguez-Estrada, M.T.; Muste, S.; Lercker, G. Thiobarbituric acid reactive substances in flavoured phytosterol-enriched drinking yogurts during storage: formation and matrix interferences. Eur. Food Res. Tech. 2016, 242, 431-439. [CrossRef]

53. Castro, P.; Millán, R.; Penedo, J.C.; Sanjuán, E.; Santana, A.; Caballero, M.J. Effect of storage conditions on total volatile base nitrogen determinations in fish muscle extracts. J. Aquat. Food Prod. Technol. 2012, 21, 519-523. [CrossRef]

54. Sikorski, Z.E.; Kołakowska, A.; Pan, B.S. The nutritive composition of the major groups of marine food organisms. In Seafood: Resources, Nutritional Composition, and Preservation; Sikorski, Z.E., Ed.; CRC Press: Boca Raton, FL, USA, 1990; pp. 55-76.

55. Ruiz-Capillas, C.; Herrero, A.M.; Jiménez-Colmenero, F. Determination of volatile nitrogenous compounds: ammonia, total volatile basic nitrogen, and trimethylamine. In Flow Injection Analysis of Food Additives; Ruiz-Capillas, C., Nollet, L.M.L., Eds.; CRC Press/Taylor and Francis Group: Boca Raton, FL, USA, 2015; pp. 659-674.

56. European Union. Commission Regulation (EC) No. 2074/2005 of 5 December 2005 laying down implementing measures for certain products under Regulation (EC) No. 853/2004 of the European Parliament and of the Council and for the organisation of official controls under Regulation (EC) No. 854/2004 of the European Parliament and of the Council and Regulation (EC) No. 882/2004 of the European Parliament and of the Council, derogating from Regulation (EC) No. 852/2004 of the European Parliament and of the Council and amending Regulations (EC) No. 853/2004 and (EC) No. 854/2004. Off. J. Eur. Union 2005, 48, $27-59$.

57. Non-Sensory Assessment of Fish Quality; Torry Advisory Note No. 92; Torry Research Station, MAFF: Aberdeen, UK, 1989; pp. 1-6.

58. Bystedt, J.; Swenne, L.; Aas, H.W. Determination of trimethylamine oxide in fish muscle. J. Sci. Food Agric. 1959, 10, 301-304. [CrossRef]

59. Cheng, J.H.; Sun, D.W.; Pu, H.; Zhu, Z. Development of hyperspectral imaging coupled with chemometric analysis to monitor $K$ value for evaluation of chemical spoilage in fish fillets. Food Chem. 2015, 185, 245-253. [CrossRef] [PubMed]

60. European Union. Regulation (EC) No. 1935/2004 of the European Parliament and of the Council of 27 October 2004 on materials and articles intended to come into contact with food and repealing directives 80/590/EEC and 89/109/EEC. Off. J. Eur. Union 2004, 47, 4-17.

61. European Union. Commission Regulation (EC) No. 450/2009 of 29 May 2009 on active and intelligent materials and articles intended to come into contact with food. Off. J. Eur. Union 2009, 52, 3-11.

62. European Union. Regulation (EC) No. 1333/2008 of the European Parliament and of the Council of 16 December 2008 on food additives. Off. J. Eur. Union 2008, 51, 16-33.

(C) 2018 by the authors. Licensee MDPI, Basel, Switzerland. This article is an open access article distributed under the terms and conditions of the Creative Commons Attribution (CC BY) license (http://creativecommons.org/licenses/by/4.0/). 